\title{
A Matching Problem between the Front Fan and Aft Fan Stages in Adaptive Cycle Engines with Convertible Fan Systems
}

\author{
Xin Meng, Zhili Zhu, Min Chen * and Yihao Xu
}

\section{check for}

updates

Citation: Meng, X.; Zhu, Z.; Chen, M.; Xu, Y. A Matching Problem between the Front Fan and Aft Fan Stages in Adaptive Cycle Engines with Convertible Fan Systems. Energies 2021, 14, 840. https:// doi.org/10.3390/en14040840

Received: 12 January 2021

Accepted: 2 February 2021

Published: 5 February 2021

Publisher's Note: MDPI stays neutral with regard to jurisdictional claims in published maps and institutional affiliations.

Copyright: (c) 2021 by the authors. Licensee MDPI, Basel, Switzerland. This article is an open access article distributed under the terms and conditions of the Creative Commons Attribution (CC BY) license (https:/ / creativecommons.org/licenses/by/ $4.0 /)$.
School of Energy and Power Engineering, Beihang University, Beijing 100191, China; mengxin871006@buaa.edu.cn (X.M.); zhuzhili@buaa.edu.cn (Z.Z.); 11041119@buaa.edu.cn (Y.X.)

* Correspondence: chenmin@buaa.edu.cn; Tel.: +86-136-9138-3803

\begin{abstract}
In the process of studying the steady-state performance and component matching of adaptive cycle engines with convertible fan system, it was found that the front fan and aft fan stage have a unique matching problem when the mode select valve is closed and engine is operating at higher Mach number conditions. The cause of this matching problem was studied with numeric simulation in this paper. Based on the features of adaptive cycle engines with convertible fan system, the possible methods and their feasibilities of solving this matching problem were also discussed. According to the results, the flow rate adjustment capacity of the aft fan stage directly determines the occurrence and severity of this matching problem. The matching problem can be ameliorated in some extent by either reducing the design second bypass ratio or adjusting the variable geometry mechanisms, but it cannot be completely solved at the aspect of component matching mechanism.
\end{abstract}

Keywords: adaptive cycle engine with convertible fan system; matching mechanism; front fan; aft fan stage

\section{Introduction}

Adaptive cycle engines (ACEs) are an advanced aero gas turbine engine, which is being considered as the power plant of future military fighters [1]. At the same time, it had also been demonstrated that it can be used for other kinds of aircrafts such as supersonic commercial transports [2]. Therefore, it is a power plant with wide application prospect in the future.

The ACE concept inherits the features and was developed from the variable cycle engine (VCE) concept [3-6], which was first proposed in the 1950s. In the beginning, it was put proposed to solve the problem that the aero gas turbine engine could not take into account the high-speed and low-speed performance at the same time, and its main application prospect was demonstrated to improve the engine's multi-mission adaptability [5]. In the following 60 years, the flight environment of aircraft has changed a lot, and the complexity and diversity of flight missions had also been significantly improved. Therefore, the VCE concept was also constantly being upgraded and facing new challenges [4-7].

Variable cycle technologies used in VCE concepts were accumulating continuously during the course of achieving the new requirements. Driven by the technological advancements, the VCE concept was no longer satisfied with the compromise of multi-condition performance with some performance sacrifices [5], and its aim gradually turned to achieve optimized and better performance at different operating conditions [8-10]. The ACE concept was born from this background. In essence, ACE also changes the engine performance by changing the thermodynamic cycle of the engine, yet it can still be classified in the VCE concept category.

The ACE concepts which have been put forward were still gas turbine engines using conventional hydrocarbon fuels [2]. As a VCE, ACE has both higher thrust at high-speed conditions and lower specific fuel consumption at low-speed conditions than those conventional cycle gas turbine engine [5]. Therefore, ACE has a better overall fuel efficiency 
of the whole propulsion system. As an upgraded VCE, ACE is considered to be superior to the double bypass engine (DBE) [4,6], which is a type of VCE concept demonstrated to improve fuel efficiency by prototypes such as the GE21 and YF120. This improvement of fuel efficiency is of great significance for future aircraft to improve the range and extend the hang time [11].

During the development of the ACE concept, many different ACE configurations have been proposed [2], and several of them had been studied to varying degrees [12-15]. Among them, ACE with fan-on-blade (FLADE) and core drive fan stage (CDFS)are representative and put forward earlier [2,12]. In this configuration, a FLADE and an additional bypass with independent nozzle are added to a DBE. The purpose of this modification is to further enhance the active adjustment capacity of the engine. No matter which configuration is used, ACE has more bypasses, and there is corresponding compressing component upstream of each bypass. Because the air flows into the core engine and bypasses flow through different amount of compressing components, their flow rate, total temperature and total pressure which are important to produce thrust, are all different. ACE can change the overall performance of the engine over a wide range by actively adjusting the air flow rate of the core engine and each bypass. Although DBE can also realize such active adjustment of flow rate and pressure ratio, compared with ACE which has more bypasses, its adjustment range and adjustment flexibility are both at a lower level. Due to its excellent adjustment ability capacity, ACE can operate with higher efficiency in a wide flight envelope. It is of great benefit to improve the performance of the whole propulsion system and enhance the fuel economy of the aircraft [2,11-14].

Although the working principles of the different ACE concepts are generally similar, there are still many differences in their specific operation and component matching [12-22]. At present, not all ACE concepts have been studied in depth, and some important research results of ACE have not been published. Consequently, there is still a lot of research work of ACE concept needed to be deal with. According to the general R\&D experience of aero gas turbine engine, study on the working principles and component matching features are the basic parts in the development process of a specific configuration, and has important guiding significance for the feasibility demonstration, the configuration selection and the following R\&D [18,23-26]. Even if the candidate configuration is quit, some of its technologies will become important technical accumulation for the following R\&D process. Therefore, it is of great and irreplaceable importance to study the overall performance and component matching features of a specific ACE configuration.

Unlike some other power plants, ACE does not have a rated operating state. It can work stably at any certain rotation speed under many different flight conditions [12,27]. Then, the steady-state performance of ACE is composed of the engine performance and the component matching relations at those conditions. Because the operating time of steady state is the majority of the ACE operating cycle, the study on the steady-state performance of ACEs should be the focus of the research on their overall performance and component matching.

The steady-state performance research of a gas turbine engine mainly depends on numerical simulation, operation data accumulation and test-bed tests $[23,26]$. With the development of numerical computing technologies, numeric simulation plays an increasingly important role in the study on engine steady-state performance. At present, the three-dimensional model [28-30] and zero-dimensional model [26,31,32] of an engine are commonly used in the numeric simulation processes. The steady-state performance numeric simulation with three-dimensional model is a method to simulate the engine by establishing a fine engine flow channel model according to the specific structure and size of the engine [28-30,33,34] and using computational fluid dynamics (CFD) technologies to carry out thermodynamical calculation of the whole engine [35-37]. This method has high complexity, requires a huge amount of calculation, and it depends on the specific structure of the engine, and the accuracy of both the model and the CFD algorithms will have a direct impact on the calculation results [35-37]. Moreover, in the demonstration stage of an 
engine concept, it is difficult to use this model to calculate the steady-state performance because there is neither specific structure nor accurate size data of the engine. Unlike the numeric simulation with three-dimensional model, that with zero-dimensional model does not depend on the size data of the engine. Each part of the engine is treated as a 'black box' in the process. The components are related by the section parameters and the relations of either flow-rate continuation or power balance, in order to calculate the thermodynamical performance of the whole engine with the characteristics of each component [23,26,38]. This method has the advantages of a simple model and less calculations. The algorithms used in this method have been demonstrated to have good convergence $[12,26,38,39]$. Without a specific prototype, this method can still calculate and analyze the steady-state performance by using the general characteristics of the components [12-15,39-43]. Therefore, the zerodimensional model numeric simulation method is considered to have strong practicability and flexibility in the preliminary R\&D stage of gas turbine engine $[23,26,27,39-43]$.

In this paper, an ACE with convertible fan system (CFS) [15,44] was studied with the zero-dimensional model numeric simulation method. A significant feature of this ACE configuration is that most of the compressing components which play an important role in the adjustment of flow rate and pressure ratio are centrally designed on the lowpressure shaft, while only a conventional core engine is reserved on the high-pressure shaft. This design makes it possible for ACE to use the same core engine design as other conventional cycle gas turbine engines. This core-derivative design method, which uses a single well-performance core engine to match different low-pressure components [45-48], has a very important practical value while the $R \& D$ cost of aero gas turbine is rapidly increasing $[47,48]$. Because of CDFS in other ACE configurations, its core engine has been seriously limited in the development of derivative models. Therefore, ACE with CFS is considered as a potential configuration which is worth discussing in detail.

In the process of studying the steady-state performance of ACE with CFS, a matching problem between the front fan and aft fan stage (AFS) was found. This problem occurs at the condition of high altitude and high speed flight when the engine works in the small bypass ratio mode and it will seriously affect the aerodynamic stability of the compressing components. According to the basic operating principles of VCE, when operating at high altitude and high-speed conditions, the engine should switch to a lower bypass ratio mode to ensure a greater specific thrust $[2-6,12,13,15,18,44]$. However, this matching problem restricts the operation of low bypass ratio mode at high altitude and high-speed conditions, which is contrary to the design aim of ACE. Therefore, it is very important to study the matching mechanism of engine in this matching problem by deeply analyzing the matching state of components, explaining the causes of the problem and exploring the methods to solve the problem.

In this paper, the 'Introduction' section introduces the necessity of studying and discussing the steady-state performance and component matching features of ACE with convertible fan system. Section 2 introduces the basic configuration, working principle, operating mode division and numeric simulation modeling method of ACE with convertible fan system. Section 3 introduces a matching problem between the front fan and AFS found in the steady-state performance research of ACE, and analyzes the influence of the problem on the component matching in detail. Section 4 presents the calculation results and discussions of the impacts of the general characteristics of compressing components on the matching problem. Section 5 presents the calculation results and discussions of the impacts of design cycle parameter on the matching problem. Section 6 presents the calculation results and discussions of the impacts of adjusting variable geometry mechanisms on the matching problem. The final section draws the conclusions.

\section{Adaptive Cycle Engine with Convertible Fan System}

\subsection{Engine Structure}

The ACE studied in this paper is a double-shaft turbofan. Its high pressure system is a complete conventional core engine (also known as gas generator in some kinds of 
gas turbine), while its low-pressure system is composed of low pressure turbine and an extremely sophisticated fan system (shown in Figure 1). The compressing part of this fan system is made up by a single-stage fan-on-blade (FLADE), a multi-stage front fan (FF) and an aft fan stage (AFS). There are also several variable geometry structures which can be actively adjusted to change both the bypass ratios and pressure ratios of the whole compressing process. Therefore, such a fan system is an is the key component of this ACE configuration to realize its variable cycle functions, and was defined as convertible fan system (CFS) when this configuration was proposed.

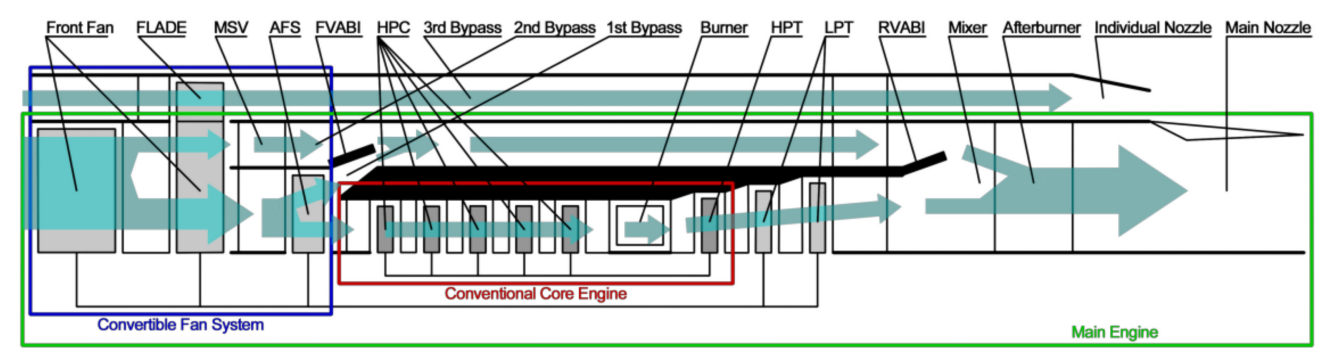

Figure 1. The Simplified Cross Section of Configuration and Flow Paths of Adaptive Cycle Engine with Convertible Fan System.

The engine flow paths are divided by CFS into one inner flow path (core engine flow path) and three bypass flow paths These three bypasses are defined as the first bypass, the second bypass and the third bypass in order from the inside to the outside (shown in Figure 1). As a result, five bypass ratios, named the first bypass ratio, the second bypass ratio, the third bypass ratio, main engine bypass ratio and overall bypass ratio in order, are also defined as shown in Equations (1)-(5):

$$
\begin{gathered}
b p r_{1}=\frac{\dot{m}_{a i r, A F S}-\dot{m}_{a i r, H P C}}{\dot{m}_{a i r, H P C}} \\
b p r_{2}=\frac{\dot{m}_{a i r, F F}-\dot{m}_{a i r, A F S}}{\dot{m}_{a i r, A F S}} \\
b p r_{3}=\frac{\dot{m}_{a i r, F L A D E}}{\dot{m}_{a i r, F F}} \\
b p r_{\text {main }}=\frac{\dot{m}_{a i r, F F}-\dot{m}_{a i r, H P C}}{\dot{m}_{a i r, H P C}}=\left(1+b p r_{1}\right)\left(1+b p r_{2}\right)-1 \\
b p r_{s}=\frac{\dot{m}_{\text {air }, A F S}+\dot{m}_{a i r, F L A D E}-\dot{m}_{a i r, H P C}}{\dot{m}_{a i r, H P C}}=\left(1+b p r_{1}\right)\left(1+b p r_{2}\right)\left(1+b p r_{3}\right)-1
\end{gathered}
$$

Among them, $b p r_{1}$ is the first bypass ratio, $b p r_{2}$ is the second bypass ratio, $b p r_{3}$ is the third bypass ratio, $b p r_{\text {main }}$ is the total bypass ratio of main engine (as shown in Figure 1), $b p r_{S}$ is the overall bypass ratio, $\dot{m}_{a i r, F F}$ is the air flow rate through Front Fan, $\dot{m}_{a i r, A F S}$ is the air flow rate through AFS, $\dot{m}_{a i r, H P C}$ is the air flow rate through high pressure compressor, and $\dot{m}_{\text {air,FLADE }}$ is the air flow rate through FLADE.

The front variable area bypass injector (FVABI) and rear variable area bypass injector (RVABI) in this ACE configuration both have similar structures and functions to those in DBE. Conventional core engine (including high pressure compressor, burner and high pressure turbine) and low pressure turbine have the same structure and function as those in conventional twin-shaft gas turbine engine.

\subsection{Operating Modes}

The mode select valve (MSV) designed at the inlet of the second bypass and the variable FLADE are two important variable geometry mechanisms for operating mode 
division. MSV is driven by pressure difference between the outlet section of front fan and the second bypass, and it could be completely closed with enough pressure difference. When it is open, air flow from front fan could flow into both AFS and the second bypass; on the contrary, all the air flow form front fan has flow into AFS. Variable FLADE, which could be adjusted to different inlet guide vane angle, would change the air flow rate through the third bypass more flexibly. Especially, while its guide vane is turned down to an extremely small angle $\left(-85^{\circ}\right)$, there is little air flow through the third bypass and FLADE would hardly boost the air flow. Therefore, while the FLADE guide vane is at its minimum angle $\left(-85^{\circ}\right)$, the third bypass could be approximately considered as closed. While FLADE guide vane is at a angle greater than $-85^{\circ}$, the third bypass could be considered as open.

Four different operating modes could be divided by the different states of both MSV and the third bypass, as the definitions of operating modes in the previous studies of ACE [12-14]. The operating mode with both MSV and the third bypass closed is defined as Mode 1; the operating mode with MSV open and the third bypass closed is defined as Mode 2; the operating mode with MSV closed and the third bypass open is defined as Mode 13; the operating mode with both MSV and the third bypass open is defined as Mode 3. This division of operating modes can not only facilitate the establishment the steady-state simulation model, but also facilitate the analysis of component matching.

According to the above definitions of the four operating modes, Mode 3 has the largest total bypass ratio, and Mode 1 has the smallest total bypass ratio. Therefore, according to the basic working principle of VCE, Mode 3 is more suitable for low-speed flight, while M1 mode is more suitable for high-speed flight.

\subsection{Numeric Simulation Model}

A zero-dimensional component-level simulation code of ACE with CFS is programmed referring to an existing simulation code of VCE. This VCE simulation code had been checked by a commercial software GasTurb 10, and the calculation differences of both design point and off-design points between them are all less than $2 \%$. As a result, the computation accuracy of simulation code is demonstrated satisfy for technical research on the steady-state performance of ACE with CFS. The overall performance parameters of the engine, the thermodynamical and geometry parameters of each characteristic section along the flow channels, the matching point parameters of each component, the surge margin of each compressing component and other parameters can be calculated by this numerical simulation code.

\subsection{Design Point and Design Cycle Parameters}

Different from conventional gas turbine engine, ACE has several operating modes. Therefore, it is necessary to determine the operating mode of the engine used at the design point before determining the flight condition of design point. Generally, in the thermodynamical calculation of engine design point, it is necessary to be able to calculate and determine the geometric size of the characteristic section of all flow channels of the engine. In ACE, when the engine works in Mode 1, Mode 2 or Mode 13, one or both of the third bypass and the MSV are closed. Therefore, it is impossible to calculate the geometric size of the inlet section of either the third bypass or the second bypass through the thermodynamic calculation of the design point. As a result, Mode 3 is the only operating mode that can be selected for design point calculation.

Mode 3 is an operating mode with large overall bypass ratio. According to the basic working principle of ACE, the advantage of Mode 3 is mainly in the low-speed flight region. Therefore, it is more suitable to choose a low-speed condition as the engine design point. Considering that the design point of military turbofan engine is generally chosen at sea level static state in order to better calibrate the maximum take-off thrust, which is one of the key performance indexes, the design point of ACE studied in this paper is finally chosen at sea level static state. Table 1 lists some of the main design cycle parameters. 
Table 1. Main Design Cycle Parameters of Adaptive Cycle Engine.

\begin{tabular}{cc}
\hline Design Cycle Parameter & Value \\
\hline Maximum Turbine Entry Temperature & $2100 \mathrm{~K}$ \\
Throttle Ratio & 1.15 \\
Pressure Ratio of FLADE & 2.00 \\
Pressure Ratio of Front Fan & 2.91 \\
Pressure Ratio of AFS & 1.40 \\
The First Bypass Ratio & 7.85 \\
The Second Bypass Ratio & 0.20 \\
The Third Bypass Ratio & 0.40 \\
\hline
\end{tabular}

A throttle ratio greater than 1 is designed to leave enough heating allowance in the main burner, in order to improve the engine performance at high speed. The choice of the three bypass ratios is to make the engine give better consideration to both the greater thrust in high-speed flight and the lower fuel consumption in low-speed flight.

\subsection{Variable Geometry Mechanisms}

In this study, the variable geometry mechanisms mainly considered include FLADE, AFS, high pressure compressor, high pressure turbine, low pressure turbine, RVABI and main nozzle.

Corresponding to these seven variable geometry mechanisms, there are seven adjusting variables for the control schedule design, which are inlet guide vane angle of FLADE, inlet guide vane angle of AFS, inlet guide vane angle of high pressure compressor, flux coefficient of inlet guide vane throat of high pressure turbine, flux coefficient of inlet guide vane throat of low pressure turbine, area coefficient of RVABI, and area coefficient of main nozzle throat. According to those component characteristics used in this study, the lower and upper limit of each adjusting variable could be determined as listed in Table 2.

Table 2. Adjustment Ranges of Main Adjusting Variables.

\begin{tabular}{ccc}
\hline Adjusting Variable & Lower Limit & Upper Limit \\
\hline Inlet guide vane angle of FLADE & $-85^{\circ}$ & $5^{\circ}$ \\
Inlet guide vane angle of AFS & $-45^{\circ}$ & $0^{\circ}$ \\
$\begin{array}{c}0^{\circ} \\
\text { Inlet guide vane angle of high pressure compressor } \\
\text { Flux coefficient of inlet guide vane throat of high } \\
\text { pressure turbine }\end{array}$ & $-20^{\circ}$ & 1.10 \\
Flux coefficient of inlet guide vane throat of low \\
$\quad$ pressure turbine & 0.90 & 1.10 \\
Area coefficient of RVABI & 0.90 & 2.00 \\
Area coefficient of main nozzle throat & 0.10 & 2.00 \\
\hline
\end{tabular}

In order to facilitate the expression in this paper, when the adjustment variable of a variable geometry mechanism changes from its lower limit to its upper limit, it is described as opening this variable geometry mechanism. On the contrary, it is described as closing this variable geometry mechanism.

\section{Matching Problem between Front Fan and Aft Fan Stage}

A significant matching problem is found in the study of the steady-state performance of this ACE. While engine is working at high Mach number flight with MSV closed, the surge margin of the front fan decreases rapidly with the increase of flight Mach number.

Because the design point of ACE studied in this paper is chosen in Mode 3, the engine working state in the mode with MSV closed (Mode 1 or Mode 13) is a typical off design condition. When the matching problem occurs, the total temperature of engine inlet is greater than $350 \mathrm{~K}$ and is further greater than $288.15 \mathrm{~K}$ which is the total temperature 
of engine inlet at the design point (sea level static). Therefore, the working state when the matching problem occurs is a typical off design state which the matching points of components are far away from their location at design point.

In detail, with the increase of flight Mach number, the total temperature of Front Fan inlet increases. Under the main fuel control schedule which maintains the physical rotation speed of the front fan in order to produce more thrust, the relative corrected rotation speed of the front fan gradually decreases. On the characteristic diagram of the front fan, the matching point moves to the low relative corrected rotation speed region. Figures 2 and 3 show respectively the change of relative corrected rotation speed of the front fan and the change of matching point of the front fan with the increase of flight Mach number.

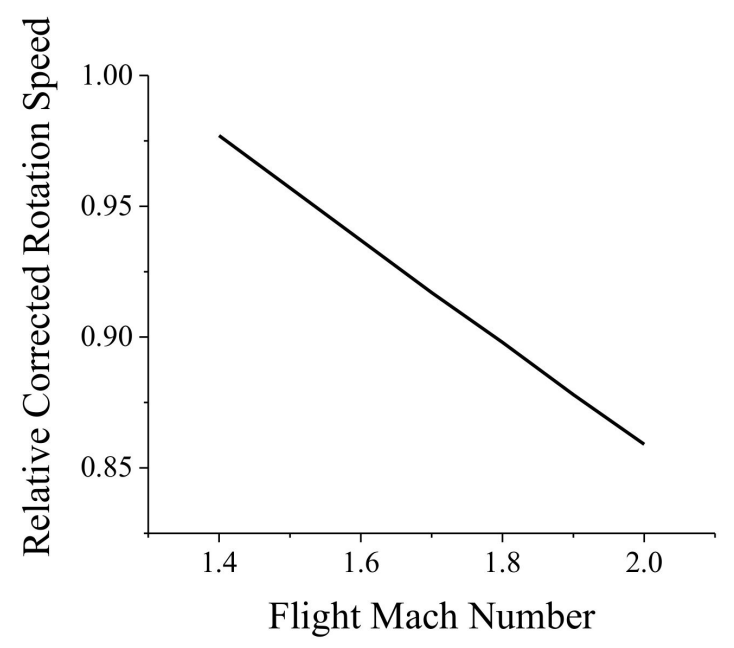

Figure 2. Relative Corrected Rotation Speed of Front Fan vs. Flight Mach Number.

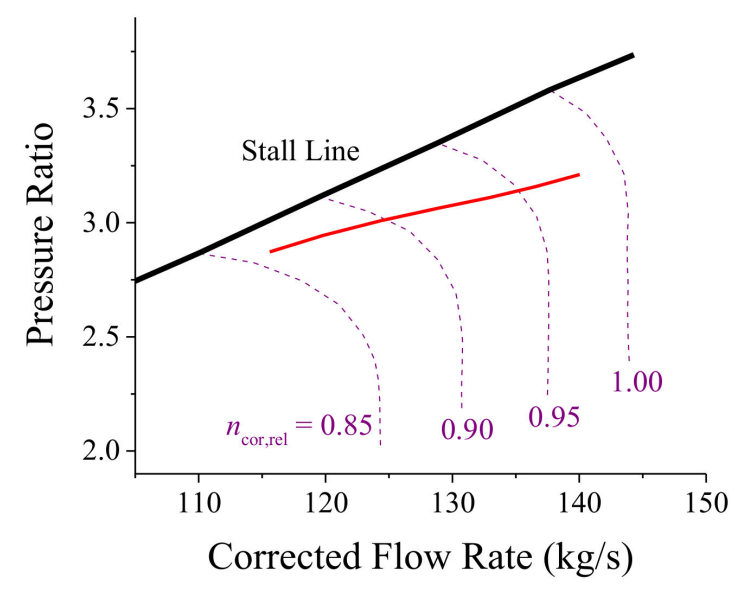

Figure 3. Matched Operating Line of Front Fan vs. Flight Mach Number.

Since MSV is closed, AFS is the only component that directly affects the flow capacity of the front fan. When the flight Mach number increases, the total temperature of the AFS inlet will also increase, resulting in a decrease in the relative corrected rotation speed of the AFS (shown in Figure 4). The matching point of the AFS moves to a lower relative corrected rotation speed region (shown in Figure 5). Due to the continuous flow restriction between the front fan and AFS, the AFS needs to increase the flow capacity as much as possible to alleviate the surge trend of the front fan, and the matching point of the AFS moves to the blocking boundary (shown in Figure 5). According to the steady-state performance calculation results, in this case, the matching point of the AFS is close to the blockage boundary, and the flow capacity is difficult to further increase, resulting in obvious blockage of AFS. 


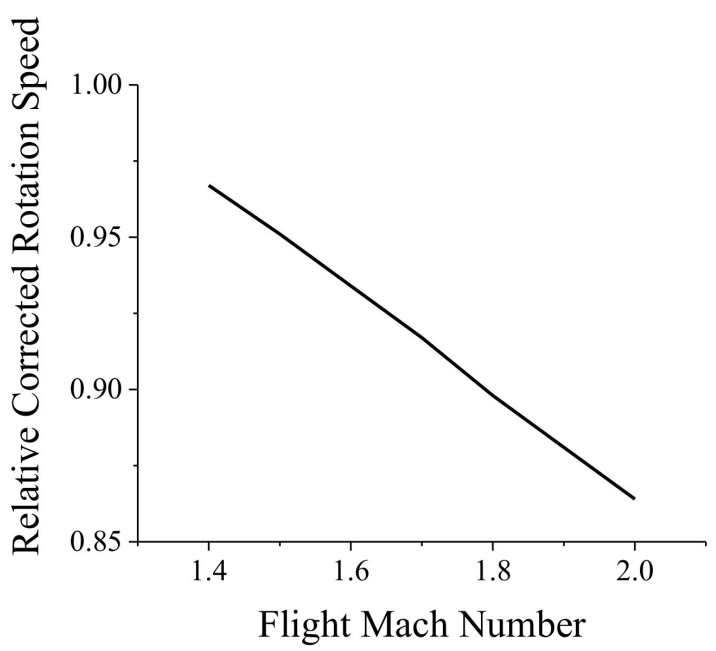

Figure 4. Relative Corrected Rotation Speed of AFS vs. Flight Mach Number.

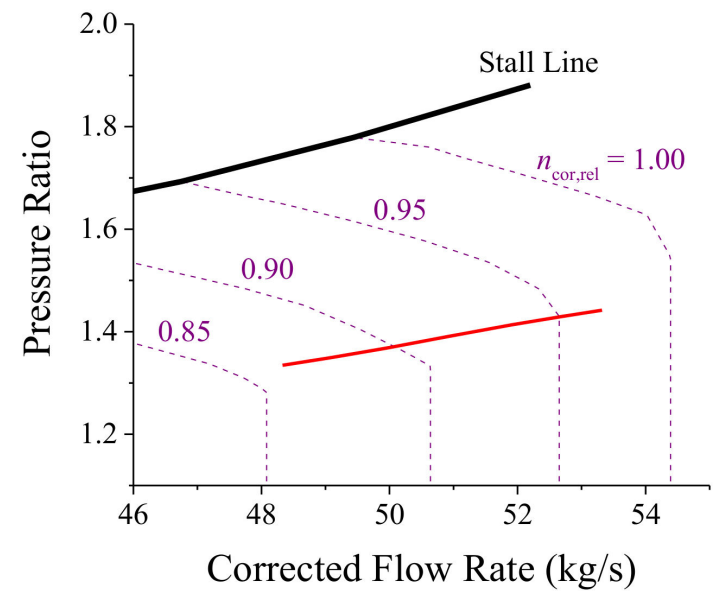

Figure 5. Matched Operating Line of AFS vs. Flight Mach Number.

The matching problem of AFS is directly related to its own structure, because in some other ACE concepts, the core drive fan stage (CDFS)structure corresponding to the AFS hardly has such a problem. In the ACE with CDFS, the front fan is connected to the lowpressure shaft and CDFS is connected in the high-pressure shaft. Under high Mach number flight conditions, the engine could enhance the flow capacity of CDFS by increasing the rotation speed slip between the high-pressure and low-pressure shafts, so as to improve the flow capacity of the front fan and prevent it from surging. This matching mechanism is similar to automatic anti-surge mechanism of the dual shaft turbojet engine. When those ACE concepts are designed with equivalent design cycle parameters, the reduction rate of relative corrected speed of CDFS is obviously less than that of AFS with the increase of flight Mach number (shown in Figure 6). Hence, CDFS has greater flow adjustment margin to alleviate the blockage of the front fan, which makes the reduction rate of the front fan surge margin relatively less (shown in Figure 7). Therefore, the matching problem between the front fan and AFS in ACE is caused by its unique convertible fan system design with AFS and is a unique matching feature of this ACE concept. 


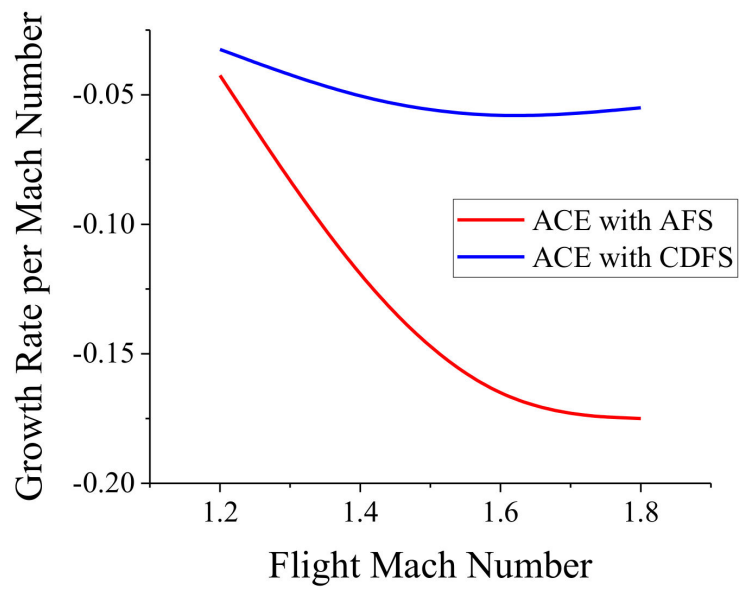

Figure 6. The Relative Corrected Rotation Speed Growth Rate Comparison between AFS and CDFS.

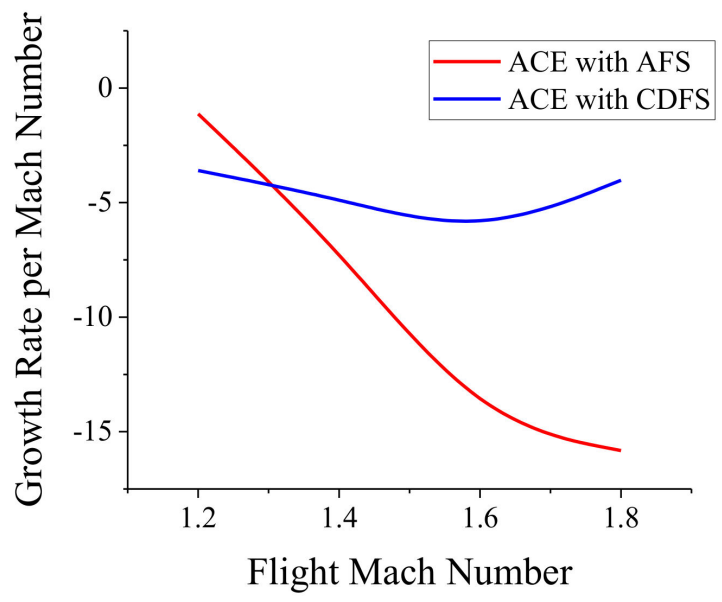

Figure 7. The Surge Margin Growth Rate Comparison of Front Fan.

This matching feature can be summarized as the front stages (front fan) surging and the rear stage (AFS) blocking under the condition of high inlet total temperature. This is similar to the "front stall \& rear blockage" (FSRB) problem of conventional singleshaft compressors. This matching problem could also be described as follows: The flow capacity of the upstream compressor is surplus while that of the downstream compressor is insufficient, and because both of them are on the same rotating shaft, it is impossible to adjust the rotation speed slip to reduce the flow capacity of the upstream compressor and improve that of downstream compressor at the same time, in order to realize flow matching. Therefore, the matching problem between the front fan and AFS is named the FSRB problem for short in this paper.

According to the working principles of ACEs, the engine needs to work in the operating mode with small bypass ratio as far as possible at high Mach number flight conditions. However, the closing of MSV leads to the FSRB problem and will affect the aerodynamic stability of the front fan under high Mach number flight conditions. Further, it will directly and seriously restrict the working envelope of this ACE. Therefore, it is of great significance to research this FSRB problem and find out a suitable solution for ACE with convertible fan system, which is strongly needed for working at a high altitude and high Mach number flight conditions.

In addition, this FSRB problem not only affects the aerodynamic stability of the front fan, but also affects the overall steady-state performance of the engine. In general, the reduction of component efficiency will reduce the overall fuel efficiency of gas turbine engine. When the FSRB problem occurs, the matching point of the front fan moves to the 
surge boundary resulting in the decrease of efficiency (shown in Figure 8), while that of AFS moves to the blocking boundary also resulting in a decrease of efficiency (shown in Figure 9). Therefore, solving this FSRB problem can improve the component efficiency of both the front fan and AFS, and thus improve the overall fuel efficiency of the engine.

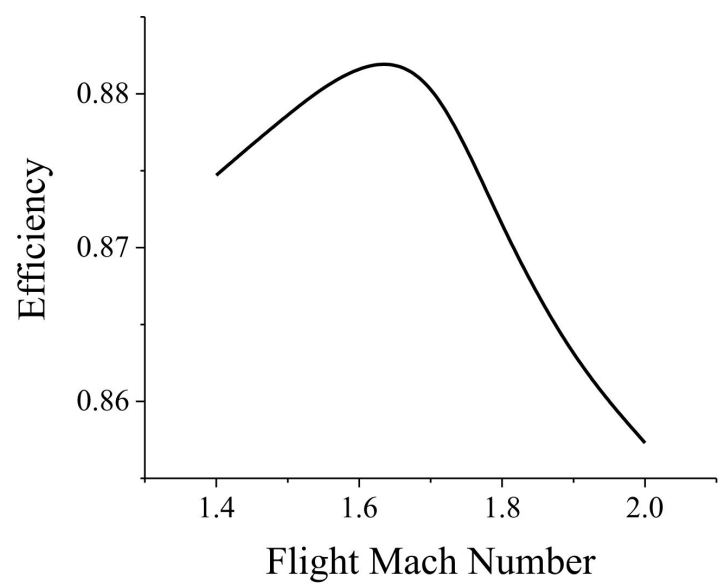

Figure 8. Front Fan Efficiency vs. Flight Mach Number.

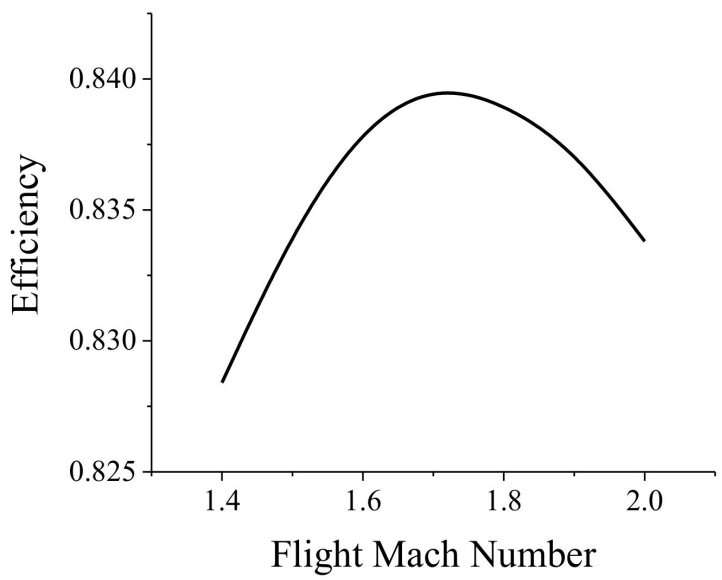

Figure 9. AFS Efficiency vs. Flight Mach Number.

\section{Impacts of Characteristics}

For aero gas turbine engines, component characteristics are the important factors that affect the engine performance and matching of components. In the previous analysis, only the position changes of the matching points on the component characteristics diagrams were simply analyzed to explain this FSRB problem. However, the position changes are only external visual expressions of the matching relations, and the matching relations of the component characteristics are the more internal cause of the engine matching. Next, the component characteristics for the analysis of this FSRB problem will be discussed in detail.

The component characteristics of the front fan and AFS have the most direct influences on this FSRB problem. In the numeric simulation of this ACE concept in this study, the front fan uses a fixed high-flow-capacity multi-stage fan characteristic as shown in Figure 10, and AFS uses a variable low-pressure-ratio CDFS characteristic as shown in Figure 11. Study on the basic properties of these two characteristics, could help analyzing the influence of this FSRB problem. 


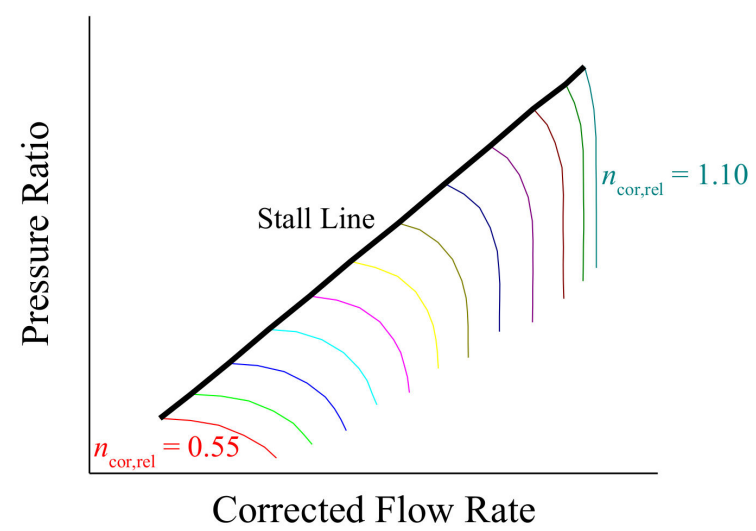

Figure 10. General Component Characteristic Diagram of Front Fan.

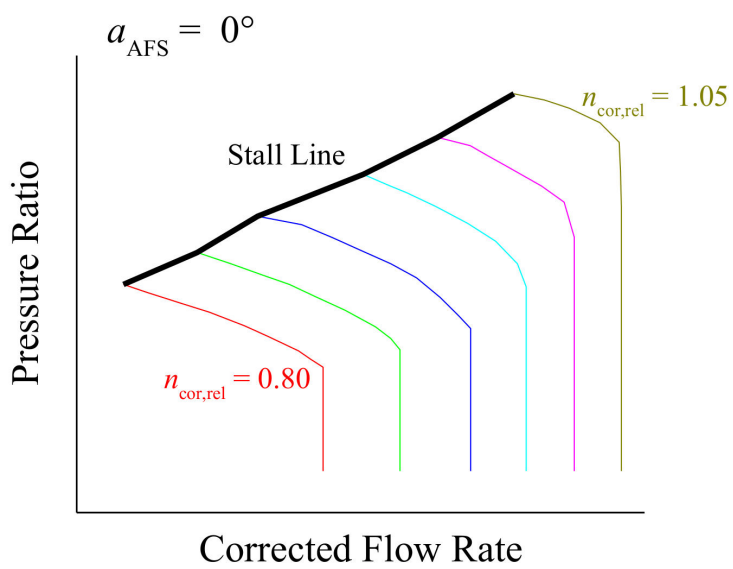

Figure 11. General Component Characteristic Diagram of AFS $\left(\mathrm{IGV}=0^{\circ}\right)$.

The main reason for FSRB problem is that the flow capacity of the front fan and AFS are not matched according to the previous discussions. In the view of flow continuity, when the MSV is opened, the AFS should be working at a smaller inlet guide vane angle, as well as the AFS should pump as much air flow through the front fan as possible by increasing the inlet guide vane angle and changing the matching point position when the MSV is closed. Consequently, in this process, the flow adjustment capacities of both the front fan and AFS directly determine whether the front fan will surge due to the blockage of AFS. As a result, analyzing the flow capacity adjustment range of the front fan and AFS, is the key to discuss the feasibility of achieving the flow matching between these two components by adjusting the flow rate.

At the condition of known relative corrected rotation speed, if the front fan maintains a certain surge margin, the theoretical limit value of flow rate adjustment of the front fan is

$$
\Delta w_{\text {cor }, \text { limit }} \%=\frac{w_{\text {cor,block }}-w_{\text {cor }, \Delta \mathrm{SM}=10}}{w_{\text {cor }, \Delta \mathrm{SM}=10}} \times 100 \%
$$

where $\Delta w_{\text {cor,limit }} \%$ is the theoretical limit percentage of flow rate adjustment, and $w_{\text {cor,block }}$ is the corrected flow rate of blockage boundary at the condition of known relative corrected rotation speed, as well as $w_{\mathrm{cor}, \Delta \mathrm{SM}=10}$ is the corrected flow rate of the point with surge margin of $10 \%$ at the condition of known relative corrected rotation speed. By analyzing the characteristics of Front Fan at different relative corrected rotation speeds, the theoretical limit percentages as shown in Table 3 can be obtained. 
Table 3. The Theoretical Limit Percentages of Flow Rate Adjustment with Certain Front Fan Surge Margin $\left(\triangle S M_{\mathrm{FF}}>10 \%\right)$.

\begin{tabular}{cccccccc}
\hline $\begin{array}{c}\text { Relative Corrected } \\
\text { Rotation Speed }\end{array}$ & 0.8 & 0.85 & 0.9 & 0.95 & 1 & 1.05 & $\begin{array}{c}\text { Average } \\
\text { Value }\end{array}$ \\
\hline $\begin{array}{c}\text { Theoretical Limit } \\
\text { Percentages }\end{array}$ & $+7.57 \%$ & $+5.26 \%$ & $+3.23 \%$ & $+1.97 \%$ & $+1.26 \%$ & $+0.32 \%$ & $+3.27 \%$ \\
\hline
\end{tabular}

According to the results in Table 3, for the front fan characteristics used in this paper, when the surge margin of the front fan is kept above $10 \%$, the adjustment range of the flow rate is small (the average value is $3.27 \%$ ). This shows that for the engine with either this front fan characteristic or a similar one, the AFS is demanded to have a strong flow rate adjustment capacity to ensure the surge margin of the front fan at high altitude and high speed.

The discussion of flow rate adjustment capacity of AFS is a little different from that of the front fan. Because of the variable geometry design, it could be divided into two parts. One is the flow rate adjustment capacity with changing inlet guide vane angle, and the other is the flow rate adjustment capacity on one certain relative corrected rotation speed line when the geometry of AFS is not adjusted.

According to the given control schedule of ACE, when the MSV is opened, the inlet guide vane angle of AFS is usually closed to $-30^{\circ}$, and it is opened to the maximum angle $\left(0^{\circ}\right)$ while the mode selection valve is closed. In the operating envelope of ACE, since the opening and closing state of MSV has little influence on relative corrected rotation speed of AFS, comparing the flow rate changes between corresponding relative corrected rotation speed line of the two different inlet guide vane angles, can directly reflect the flow rate changes caused by geometric adjustment related to MSV opening and closing status (shown in Table 4).

Table 4. The Flow Rate Changing Percentages while Inlet Guide Vane Angle of AFS Changes from $-30^{\circ}$ to $0^{\circ}$.

\begin{tabular}{cccccccc}
\hline $\begin{array}{c}\text { Relative Corrected } \\
\text { Rotation Speed }\end{array}$ & $\mathbf{0 . 8}$ & $\mathbf{0 . 8 5}$ & $\mathbf{0 . 9}$ & $\mathbf{0 . 9 5}$ & $\mathbf{1}$ & $\mathbf{1 . 0 5}$ & $\begin{array}{c}\text { Average } \\
\text { Value }\end{array}$ \\
\hline $\begin{array}{c}\text { Flow Rate Changing } \\
\text { Percentages }\end{array}$ & $+23.59 \%$ & $+24.95 \%$ & $+25.85 \%$ & $+26.51 \%$ & $+26.23 \%$ & $+26.18 \%$ & $+25.55 \%$ \\
\hline
\end{tabular}

According to the results in Table 4, when the inlet guide vane angle of AFS is increased from $-30^{\circ}$ to $0^{\circ}$, the average flow rate capacity gain of AFS is $25.55 \%$. However, with the decrease of relative corrected rotation speed, the gain decreases slowly.

The discussion of flow rate adjustment capacity on one certain relative corrected rotation speed line without geometric adjustment, could use similar method used to calculate the theoretical limit percentages of the flow rate adjustment of Front Fan. As a result, when the inlet guide vane angle is adjusted to $0^{\circ}$, the flow rate changing percentages is shown in Table 5 while the surge margin of AFS is greater than $10 \%$.

Table 5. The Flow Rate Changing Percentages of Flow Rate Adjustment with Certain AFS Surge Margin $\left(\triangle S M_{\mathrm{AFS}}>10 \%\right)$.

\begin{tabular}{cccccccc}
\hline $\begin{array}{c}\text { Relative Corrected } \\
\text { Rotation Speed }\end{array}$ & 0.8 & 0.85 & 0.9 & 0.95 & $\mathbf{1}$ & $\mathbf{1 . 0 5}$ & $\begin{array}{c}\text { Average } \\
\text { Value }\end{array}$ \\
\hline $\begin{array}{c}\text { Flow Rate Changing } \\
\text { Percentages }\end{array}$ & $+12.72 \%$ & $+11.61 \%$ & $+10.91 \%$ & $+8.98 \%$ & $+6.19 \%$ & $+3.47 \%$ & $+8.98 \%$ \\
\hline
\end{tabular}

According to the results in Table 5, the flow rate adjustment capacity of AFS on a certain relative corrected rotation speed line is up to an average value of $8.98 \%$, and is 
slightly stronger than that of the front fan. Moreover, with the decrease of relative corrected rotation speed of AFS, the flow rate changing percentage gradually increases.

Based on the discussions of the above two parts, the theoretical limit percentage of the flow rate adjustment of AFS at different conditions of MSV opening or closing state can be calculated as shown in Table 6. According to these results, at the condition of higher relative corrected rotation speed, the main factor affecting the flow rate adjustment capacity of AFS is geometric adjustment. However, at the condition of low relative corrected rotation speed, the proportion of matching point changes gradually increases among those factors affecting the adjustment capacity.

Table 6. The Theoretical Limit Percentages of Flow Rate Adjustment of AFS with Inlet Guide Vane Adjustment.

\begin{tabular}{cccccccc}
\hline $\begin{array}{c}\text { Relative Corrected } \\
\text { Rotation Speed }\end{array}$ & $\mathbf{0 . 8}$ & $\mathbf{0 . 8 5}$ & $\mathbf{0 . 9}$ & $\mathbf{0 . 9 5}$ & $\mathbf{1}$ & $\mathbf{1 . 0 5}$ & $\begin{array}{c}\text { Average } \\
\text { Value }\end{array}$ \\
\hline $\begin{array}{c}\text { Theoretical Limit } \\
\text { Percentages } \\
\text { Proportions of } \\
\text { Geometric } \\
\text { Adjustment } \\
\begin{array}{c}\text { Proportions of } \\
\text { Matching Point } \\
\text { Changes }\end{array}\end{array}$ & $64.36 .31 \%$ & $+36.56 \%$ & $+36.76 \%$ & $+35.49 \%$ & $+32.42 \%$ & $+29.65 \%$ & $+34.53 \%$ \\
\hline
\end{tabular}

This trend is also consistent with the previous analysis of FSRB problem. At the condition of lower Mach number, the relative corrected rotation speed of AFS is relatively higher, and the flow rate change caused by geometric adjustment is relatively greater. Consequently, the blockage of AFS is not obvious. But under the condition of higher Mach number, the relative corrected rotation speed of AFS is lower, and the flow rate change caused by geometric adjustment is smaller. Therefore, the flow rate adjustment capacity of changing matching point is required to take advantage of flow rate matching. The matching point of AFS is forced to move quickly to the blockage boundary, resulting in the blockage of this component.

Considering the influence of the flow rate adjustment capacity of the front fan, a preliminary estimation value of the flow rate change of both the front fan and AFS while MSV is adjusted from open to closed, can be calculated (shown in Table 7). According to these results, AFS plays a key role in the flow rate adjustment, with an average proportion of $92.00 \%$.

Table 7. The Theoretical Estimation Percentages of Flow Rate Adjustment with the Consideration of both Front Fan and AFS.

\begin{tabular}{cccccccc}
\hline $\begin{array}{c}\text { Relative Corrected } \\
\text { Rotation Speed }\end{array}$ & $\mathbf{0 . 8}$ & $\mathbf{0 . 8 5}$ & $\mathbf{0 . 9}$ & $\mathbf{0 . 9 5}$ & $\mathbf{1}$ & $\mathbf{1 . 0 5}$ & $\begin{array}{c}\text { Average } \\
\text { Value }\end{array}$ \\
\hline $\begin{array}{c}\text { Theoretical } \\
\text { Estimation Value }\end{array}$ & $+43.88 \%$ & $+41.81 \%$ & $+39.99 \%$ & $+37.47 \%$ & $+33.68 \%$ & $+29.97 \%$ & $+37.80 \%$ \\
$\begin{array}{c}\text { Proportion of Front } \\
\text { Fan }\end{array}$ & $17.26 \%$ & $12.57 \%$ & $8.08 \%$ & $5.27 \%$ & $3.74 \%$ & $1.06 \%$ & $8.00 \%$ \\
$\begin{array}{c}\text { Proportion of AFS } \\
82.74 \%\end{array}$ & $87.43 \%$ & $91.92 \%$ & $94.73 \%$ & $96.26 \%$ & $98.94 \%$ & $92.00 \%$ \\
\hline
\end{tabular}

Therefore, the flow rate adjustment capacity of AFS is the most important factor affecting the FSRB problem. Specially, flow rate adjustment capacity caused by geometric adjustment can overall improve the surge margin of the front fan when MSV is shut down. The increase of the flow rate adjustment capacity of AFS at the condition of maximum inlet guide vane angle $\left(0^{\circ}\right)$ and relatively lower relative corrected rotation speed 
region, can effectively improve the surge margin of the front fan at the high Mach number flight conditions.

An example of steady-state performance of ACE could show clearly the influence of this mismatch between component characteristics. In this example, the designed second bypass ratio is 0.4 , and the operating mode of the engine steady-state performance calculation is Mode 2 with afterburning. The difference between Mode 2 with afterburning and Mode 1 with afterburning, which is the operating mode used previously to discuss the FSRB problem, is the different state of MSV. Therefore, according to the bypass ratio calculation of the second bypass, the relative flow rate difference between the front fan and AFS, which should be considered to match by adjustment when MSV is closed, can be approximately estimated.

The second bypass ratio gradually increases with the increase of flight Mach number (shown in Figure 12). By converting the variation curve in Figure 12 to the coordinate of the relative corrected speed of AFS, the variation curve as shown in Figure 13 can be obtained. According to the comparison between this curve and the theoretical estimation percentages of the flow rate adjustment of the front fan and AFS, it can be found that this flow rate adjustment capacity could not achieve the demands of flow rate matching between those two components when MSV is shut down. Especially at the condition of lower relative corrected speed, the pumping capacity of AFS is too insufficient to allow the upstream air flow go through it. Without changing the chosen component characteristics, reducing the design second bypass ratio is considered the only way to make the flow rate adjustment capacity of those characteristics meet the matching demands.

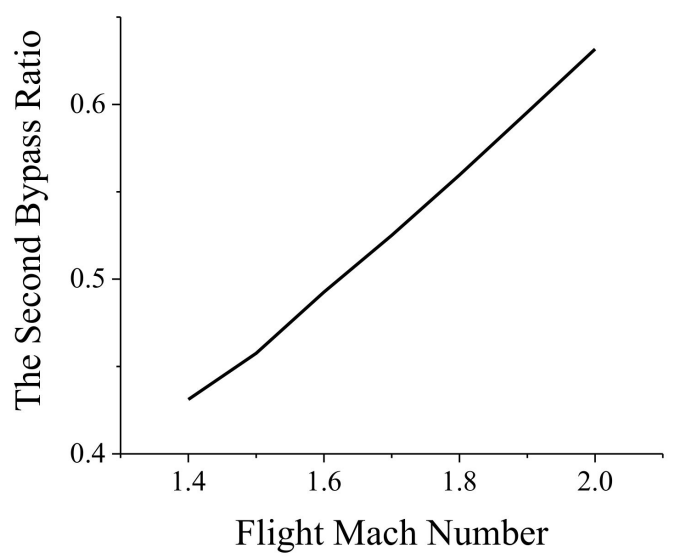

Figure 12. The Second Bypass Ratio vs. Flight Mach Number (Mode 2 with afterburning).

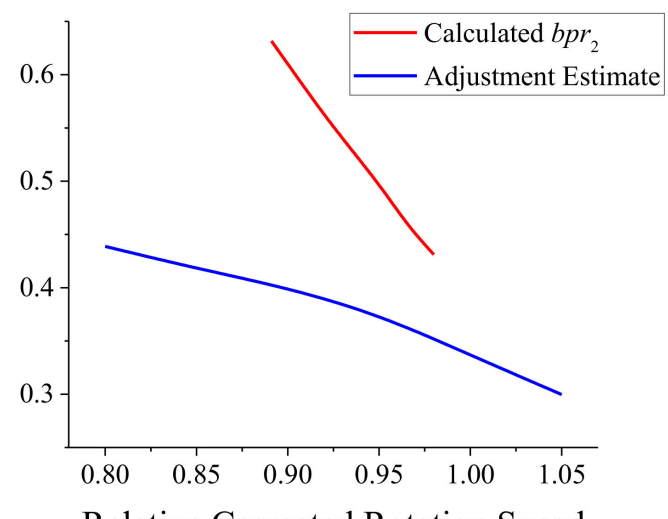

Relative Corrected Rotation Speed

Figure 13. The Second Bypass Ratio vs. Relative Corrected Rotation Speed of AFS (Mode 2 with afterburning). 


\section{Impacts of Design Cycle Parameters}

Due to the limited references about the front fan and AFS, it is not feasible to redesign the components suitable for the current design cycle parameters to solve the FSRB problem, and the only feasible way is discussing other method to solve this problem based on the existing component characteristics. Since the variable geometry components of ACE are more than those of the conventional turbofan, the selection of the design cycle parameters has a more obvious impact on the steady-state performance of the engine and the matching of various components. Especially at some conditions, different design cycle parameters will greatly affect the overall performance of the engine and the aerodynamic stability of those compressing components. According to the previous discussion on the influence of component characteristics, the adjustment of design cycle parameters should be firstly considered to discuss the feasibility and specific implementation method of solving the FSRB problem.

Through the calculation and comparison of the steady-state performance of ACE with adjusting the main design cycle parameters separately, it is found the second bypass ratio and throttle ratio are two design cycle parameters which have representative influence on the FSRB matching phenomenon. The effects of the two are discussed in detail as following.

\subsection{The Second Bypass Ratio}

According to the previous discussion, the second bypass ratio is the most direct influence on the flow matching between the front fan and AFS. The smaller design second bypass ratio, the less additional air flow required by AFS when the MSV is closed, and the burden of adjusting the flow rate of AFS is lighter.

The effect of different design second bypass ratio on turbine entry temperature in Mode 1 with afterburning is not significant (shown in Figure 14), and a greater design second bypass ratio leads to a greater overall bypass ratio of the engine (shown in Figure 15).

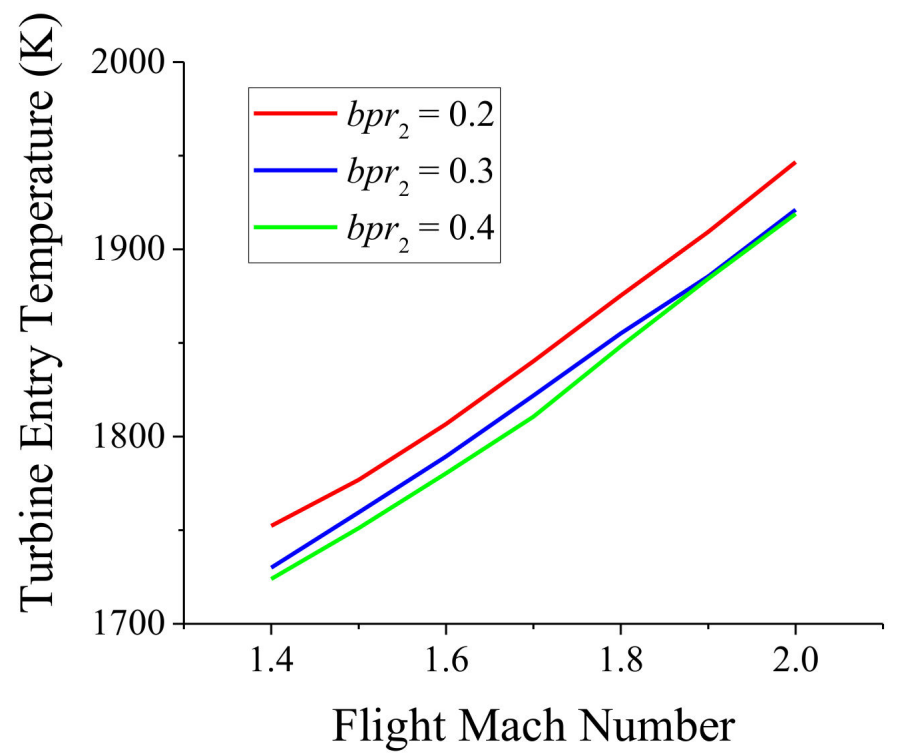

Figure 14. The Variations of Turbine Entry Temperature at the conditions of Different Second Bypass Ratios $\left(b p r_{2}\right)$. 


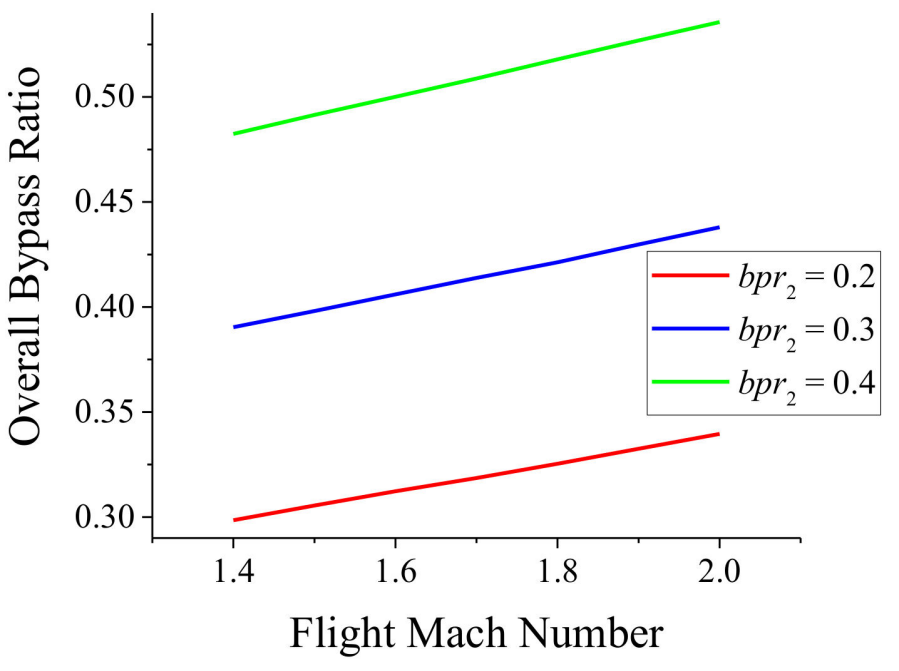

Figure 15. The Variations of Overall Bypass Ratio at the conditions of Different Second Bypass Ratios $\left(b p r_{2}\right)$.

In the case that the general component characteristics of both the front fan and AFS are given, changing the design second bypass ratio has little effect on the flow rate adjustment capacity of AFS. Therefore, when the second bypass ratio is designed with a lower value, the maximum flow capacity of AFS is relatively abundant to pump upstream air flow, and then the geometric adjustment of AFS can reduce the blockage degree of the air flow downstream of the front fan. In this case, the surge margin of the front fan is relatively greater (shown in Figure 16). Although the phenomenon of insufficient surge margin and aerodynamic instability will still occur at higher Mach number flight, sufficient surge margin can be ensured for the front fan at low and medium Mach number flight. On the contrary, a greater design of the second bypass ratio would make the FSRB problem more severe, as well as both the aerodynamic instability of the front fan and the blockage of AFS will occur at a relative lower Mach number flight.

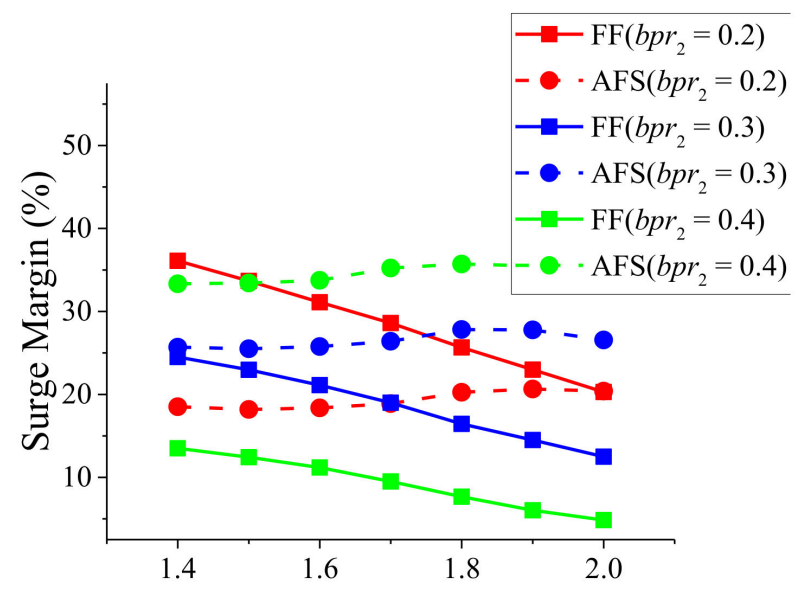

Flight Mach Number

Figure 16. The Variations of Surge Margins of Front Fan and AFS at the conditions of Different Second Bypass Ratios $\left(b p r_{2}\right)$.

On the other hand, when the secondary bypass ratio is lower, the flow capacity of AFS is relatively surplus, the matching point on its characteristic diagram is relatively far away from the blockage boundary. Therefore, its surge margin is moderate, and it could operate in a high efficiency area (shown in Figure 17). 


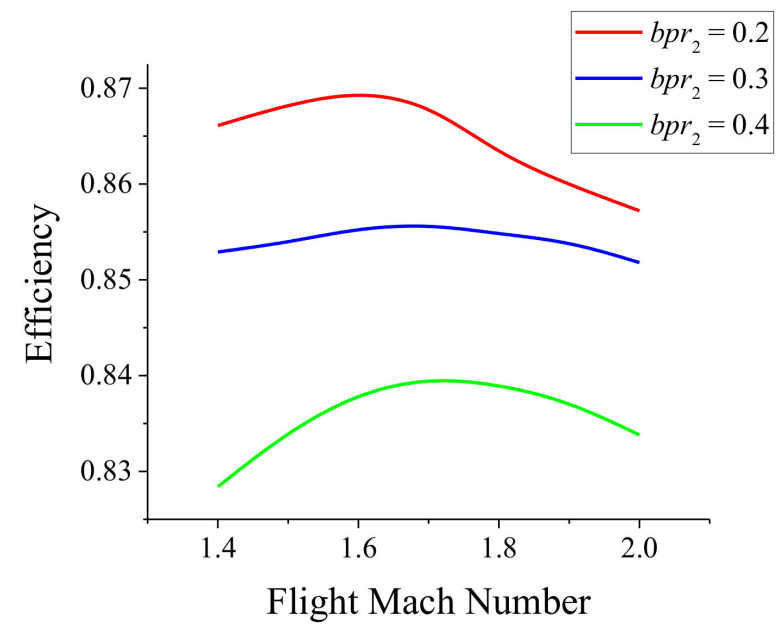

Figure 17. The Variations of AFS Efficiency at the conditions of Different Second Bypass Ratios $\left(b p r_{2}\right)$.

Figures 18 and 19 show the characteristic diagrams and matching curves of both the front fan and AFS, which are parts of steady-state performance at the condition of an altitude of $11 \mathrm{~km}$ and a Mach number range from 1.4 to 2.5, while the design second bypass ratio is 0.2 . It is found that the matching point of the front fan is still very close to the surge boundary at a higher flight Mach number, although the overall degree of surge margin of the front fan is improved by the design with lower second bypass ratio. Therefore, without changing the general component characteristics, reducing the design second bypass ratio only could alleviate the intensity of FSRB phenomenon within a certain Mach number range.

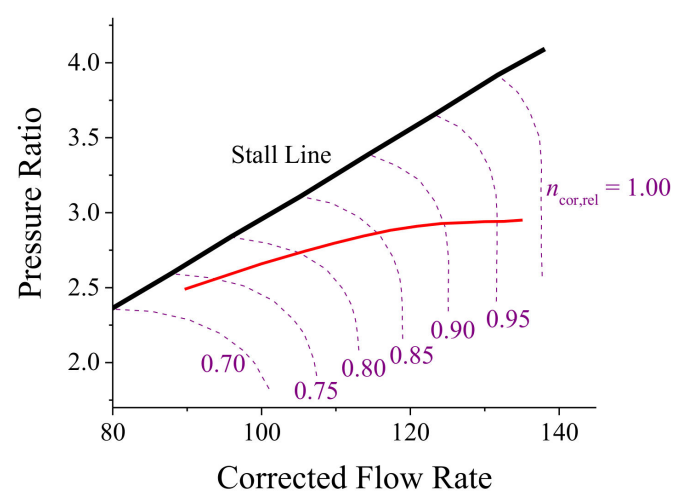

Figure 18. The Matched Operating Line of Front Fan $\left(b p r_{2}=0.2\right)$.

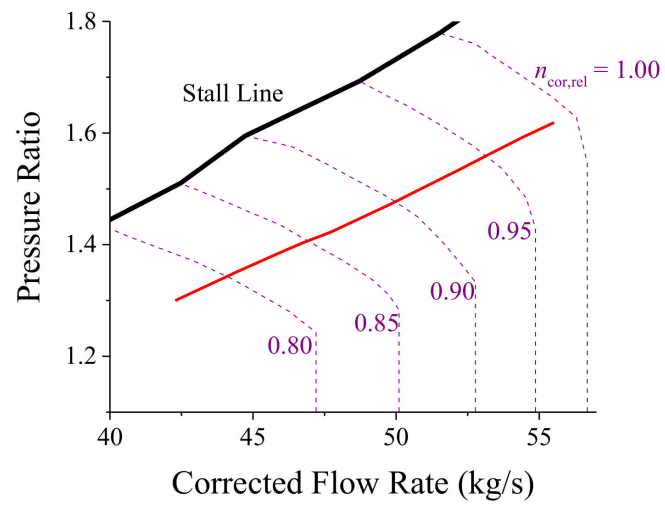

Figure 19. The Matched Operating Line of AFS $\left(b p r_{2}=0.2\right)$. 
On the whole, the influence of different design second bypass ratios on the FSRB problem, is more due to the change of the lower limit of flight Mach number at which the FSRB phenomenon start to occur. However, it does not fundamentally change the inevitability of this phenomenon from the matching mechanism.

\subsection{Throttle Ratio}

The design throttle ratio will affect turbine entry temperature at the design point, and then affect the distribution of pressure ratio or the pressure ratio of each component at the design point. Since the ACE with convertible fan system has the design requirement of supersonic cruise, its design throttle ratio should be greater than 1 to ensure that the main combustor has sufficient heating capacity at high-speed flight conditions. In the study, the upper limitation of turbine entry temperature remains unchanged. The larger the design throttle ratio, the lower turbine entry temperature at design point.

With the increase of flight Mach number, the occurrence process of FSRB problem can be divided into two stages. In the first stage, turbine entry temperature does not reach the limitation, and the main fuel control schedule of the engine is maintaining the rotation speed of the low-pressure shaft (that is the rotation speed of the front fan and AFS) unchanged. At this condition, with the increase of flight Mach number, the relative corrected rotation speed of the front fan and AFS decreases slowly. In the second stage, turbine entry temperature reaches its limitation, and the main fuel control schedule of the engine changes to maintain turbine entry temperature unchanged. At this condition, with the increase of flight Mach number, the total inlet temperatures of both the front fan and AFS continue to increase while their physical rotation speeds decrease, thus their relative corrected rotation speeds begin to decrease rapidly. According to the previous results, while the relative corrected rotation speed is reduced, the FSRB problem will become more serious. Therefore, FSRB problem deteriorates faster in the second stage than in the first stage. The effect of changing the design throttle ratio is mainly reflected in the improvement of the flight Mach number which makes the engine enter the second stage of FSRB problem.

The engine with high design throttle ratio has lower turbine entry temperature due to the reservation of larger heating margin in main combustor (shown in Figure 20). However, due to the low turbine entry temperature in Mode 1, the flight Mach number when turbine entry temperature reaches its limitation is reasonably high. In terms of the aerodynamic stability of the compressing components, according to the calculation results, the engine with high design throttle ratio has little influence on the surge margin of the front fan, while the influence on the surge margin of AFS is slightly obvious (shown in Figure 21). The larger the design throttling ratio is, the smaller the surge margin of AFS is.

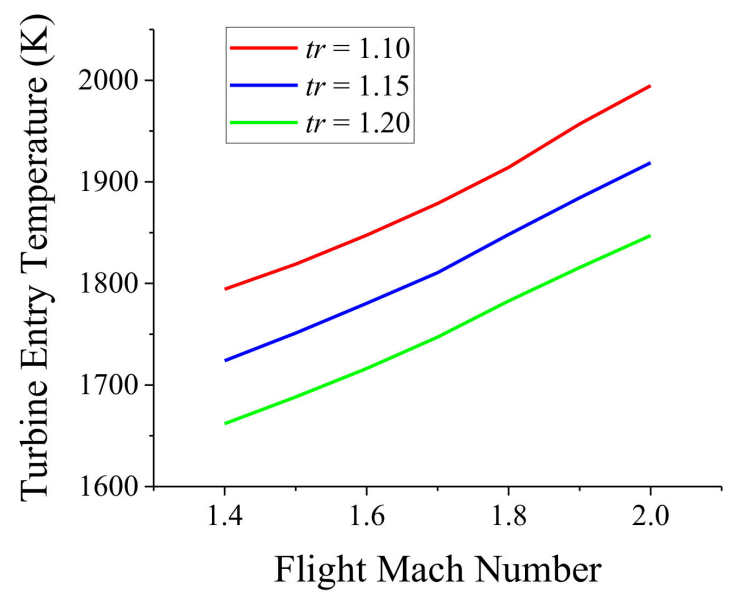

Figure 20. The Variations of Turbine Entry Temperature at the conditions of Different Throttle Ratio $(t r)$. 


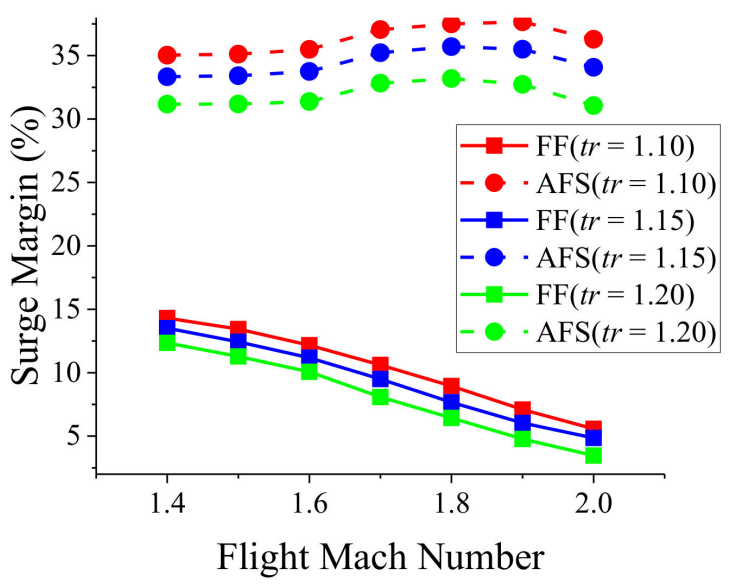

Figure 21. The Variations of Surge Margins of Front Fan and AFS at the conditions of Different Throttle Ratio (tr).

A high design throttling ratio can increase the flight Mach number which the engine enters the second stage of FSRB problem, but it will also reduce the surge margins of Front Fan and AFS at the same time. Therefore, re-choosing the design throttling ratio has little help for solving FSRB problem.

The other main design cycle parameters have little influence on FSRB problem, which will not be discussed in detail here. In conclusion, the design second bypass ratio is the key design cycle parameter to change the occurrence and intensity of FSRB problem. Its choice needs to be considered with both the overall performance requirements and component design capabilities.

\section{Impacts of Variable Area Mechanisms}

Changing the design cycle parameters, re-designing the component (replacing the component characteristics for the overall performance research) and adjusting the variable geometry mechanisms are three key means to change the engine steady-state performance and component matching relations for ACE. According to the previous discussions, the changing of design cycle parameters can ameliorate the FSRB problem, to a certain extent, especially at low and medium engine inlet total temperature. However, at the condition of both high altitude and high Mach number, which leads to a higher engine inlet temperature, the front fan still has an insufficient surge margin tooperate stably. Since the general characteristics of components cannot be replaced in this study and the influence of changing design cycle parameters to FSRB problem is limited, it is necessary to study the feasibility of ameliorating the FSRB problem by adjusting those variable geometry mechanisms of ACE.

Although seven variable geometry mechanisms are mainly considered in this paper, some of them need not be discussed when finding the solution of this matching problem.

Since the third bypass is close to the full-closed state in Mode 1, the adjustment of FLADE is not considered. Because of the closure of MSV in Mode 1, in order to pump the air flow downstream of the front fan into the core compressor as much as possible, AFS and the high-pressure compressor are generally adjusted to the maximum flow state with the maximum inlet guide vane angle. Turning down the inlet guide vanes of those two components will directly reduce their flow capacity, and cause blockage to the upstream compressing components, and then reduce their surge margins rapidly. The rapid reduction of surge margin of the front fan is obviously inconsistent with the research purpose of improving its aerodynamic stability. Therefore, the inlet guide vanes of the both AFS and high-pressure compressor are not considered to be adjusted while MSV is closed, but their maximum flow conditions are maintained.

In this part, the engine steady-state performance operating in Mode 1 with afterburning at $11 \mathrm{~km}$ altitude and flight Mach number in the range of 2.0 to 2.5 is focused and analyzed. In those calculation, considering the discussions of the design cycle parameters 
in the previous section, the design second bypass ratio is adjusted from 0.4 to 0.2 , and the design third bypass ratio is adjusted from 0.5 to 0.75 , in order to keep the overall bypass ratio of the engine at 1.52 , and other design cycle parameters remain unchanged.

\subsection{Main Nozzle}

In the total performance study of an engine, the adjustment of the main nozzle, which is a common variable geometric adjustment method of conventional gas turbine engine, is mainly represented as the changing of main nozzle throat area in most military gas turbine engine with convergent-divergent nozzle. In the component matching relations of ACE, changing the throat area of main nozzle will change the velocity and pressure of exhausting gas on the one hand, and will directly affect the outlet total pressures of the first bypass, the second bypass and the low-pressure turbine, which will further affect the matching and co-operation of all components. When MSV is closed, adjusting the throat area of main nozzle will no longer have a direct impact on the front fan, but can only indirectly affect its co-operation through the influence on low pressure turbine and AFS.

When the throat area of main nozzle is increase, the back pressures at the outlets of AFS and low-pressure turbine will both decrease, and then the boosting capability of AFS will decrease. The back pressure at the outlet of the first bypass decreases, so the first bypass ratio increases. Since the pressure ratio of low-pressure turbine also increases, the turbine entry temperature decreases to maintain the rotation speed of low-pressure shaft (shown in Figure 22), as well as the rotation speed of high-pressure shaft decreases (shown in Figure 23). The pumping capacity of high-pressure compressor becomes weaker because the rotation speed decreases; therefore, the increasing trend of the first bypass ratio becomes more significant (shown in Figure 24). However, the back pressure at the outlet of AFS is also affected by the high-pressure compressor, which makes the boosting capacity of AFS increase. As a result, the matching point of AFS which has close relation of its surge margin will change under the combined action of those two opposite trends mentioned above (shown in Figures 25 and 26).

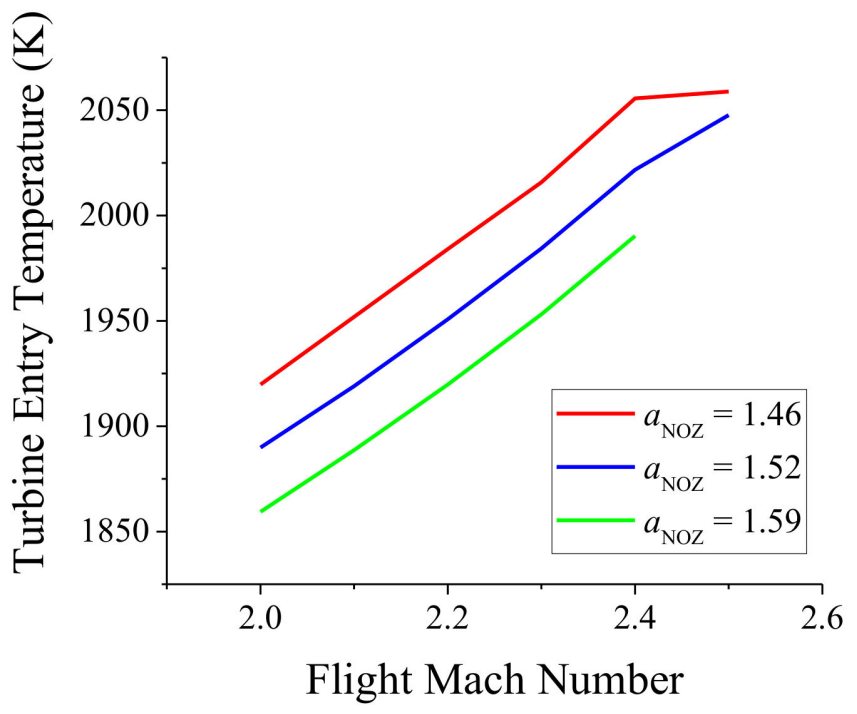

Figure 22. The Variations of Turbine Entry Temperature at the conditions of Different Throat Area Coefficients of Main Nozzle $\left(\alpha_{\mathrm{NOZ}}\right)$. 


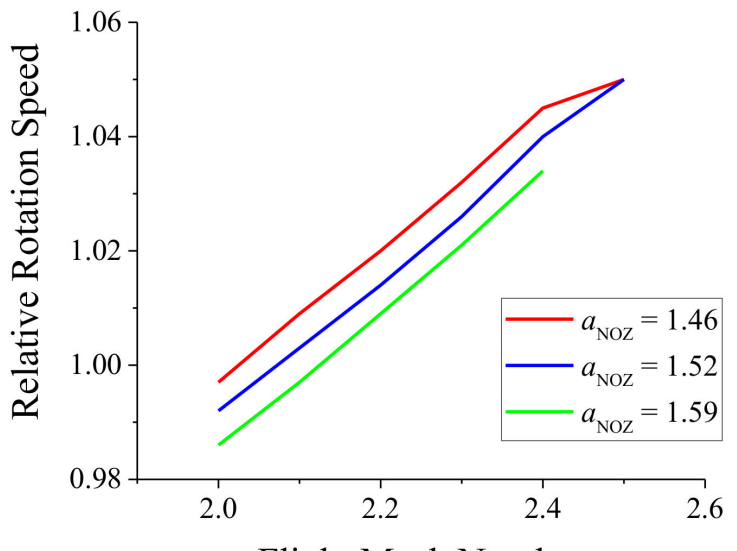

Flight Mach Number

Figure 23. The Variations of Relative Rotation Speed of High-Pressure Shaft at the conditions of Different Throat Area Coefficients of Main Nozzle $\left(\alpha_{\mathrm{NOZ}}\right)$.

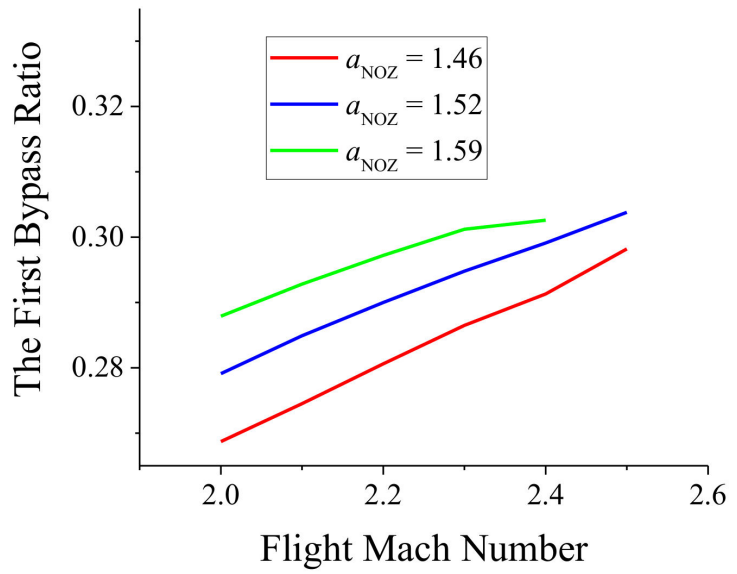

Figure 24. The Variations of The First Bypass Ratio at the conditions of Different Throat Area Coefficients of Main Nozzle $\left(\alpha_{\mathrm{NOZ}}\right)$.

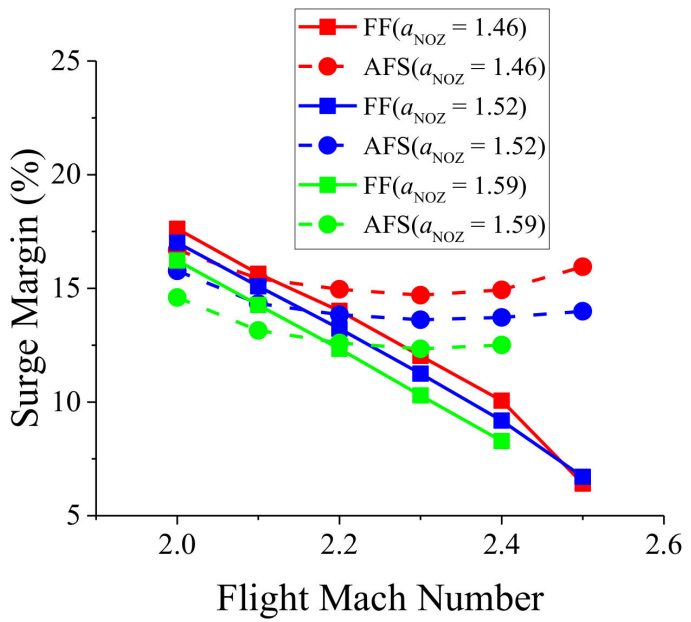

Figure 25. The Variations of Surge Margins of Front Fan and AFS at the conditions of Different Throat Area Coefficients of Main Nozzle $\left(\alpha_{\mathrm{NOZ}}\right)$. 


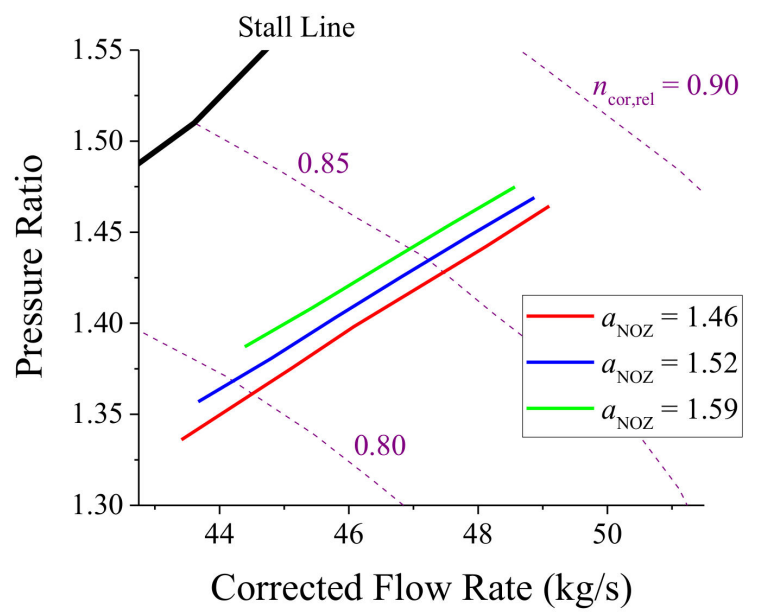

Figure 26. The Variations of the Matched Operating Lines of AFS at the conditions of Different Throat Area Coefficients of Main Nozzle $\left(\alpha_{\mathrm{NOZ}}\right)$.

According to the steady-state performance calculation results, although the matching point of AFS is affected by several factors in the opposite trends when adjusting the throat area of main nozzle, there are no significant differences in both matching point of AFS and the back pressure at the outlet of the front fan. Therefore, when MSV is closed, adjusting the main nozzle throat has little effect on the matching point of the front fan (shown in Figure 27), and it is difficult to change FSRB matching phenomenon (shown in Figure 25).

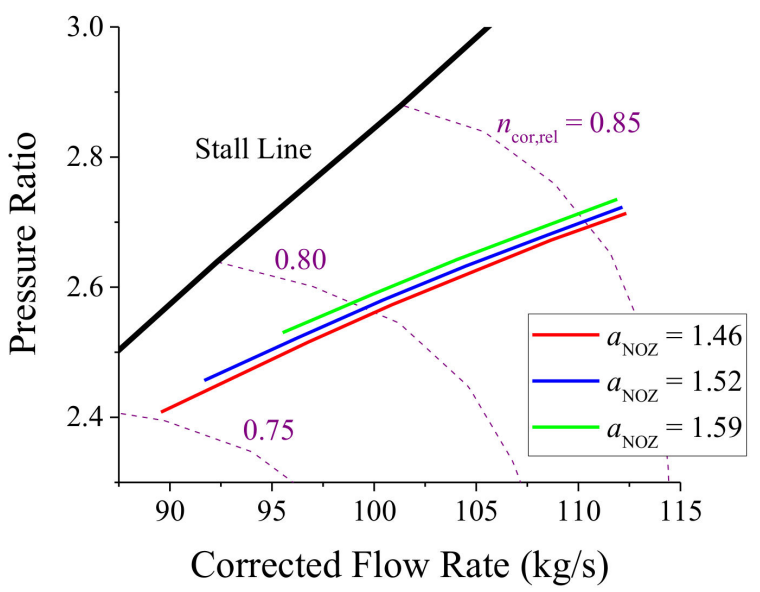

Figure 27. The Variations of the Matched Operating Lines of Front Fan at the conditions of Different Throat Area Coefficients of Main Nozzle $\left(\alpha_{\mathrm{NOZ}}\right)$.

\subsection{Rear Variable Area Bypass Injector (RVABI)}

The adjustment of RVABI can affect the back pressure at the outlet of the second bypass and the outlet of the low-pressure turbine at the same time. It is worth noting that RVABI will have opposite effects on the back pressure at the outlet of the second bypass and the outlet of the low-pressure turbine. When MSV is closed, this adjustment will directly affect the matching of AFS, but not the front fan.

The increase of RVABI area coefficient leads to a decrease of the back pressure at the outlet of the second bypass and an increase of the back pressure at the outlet of lowpressure turbine. As a result, the pressure ratio of low-pressure turbine decreases. In order to balance the power of the low-pressure shaft and maintain its rotation speed, the turbine entry temperature should increase (shown in Figure 28), and then the rotation speed of high-pressure shaft increase caused by the increase of specific output power of high-pressure turbine (shown in Figure 29). On the other hand, with the decrease of the back pressure at the outlet of the second bypass, the pressure ratio of AFS will decrease, 
and the bypass ratio of the first bypass will increase (shown in Figure 30), which will reduce the air flow into the core engine and reduce its total temperature and pressure. With the increase of turbine entry temperature, the pressure ratio of the high-pressure compressor will increase, and then the compressing power consumption will increase. Therefore, the rotation speed of high-pressure shaft will decrease. Under the combined action of those different trends, the rotation speed of high pressure shaft is not significantly changed (shown in Figure 29).

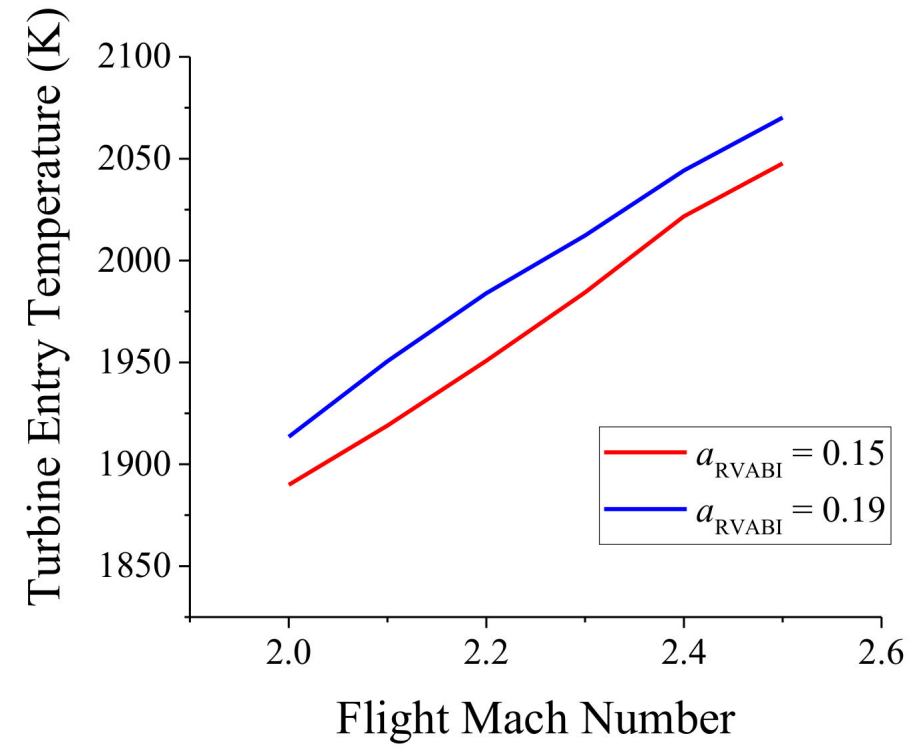

Figure 28. The Variations of Turbine Entry Temperature at the conditions of Different Area Coefficients of RVABI $\left(\alpha_{\mathrm{RVABI}}\right)$.

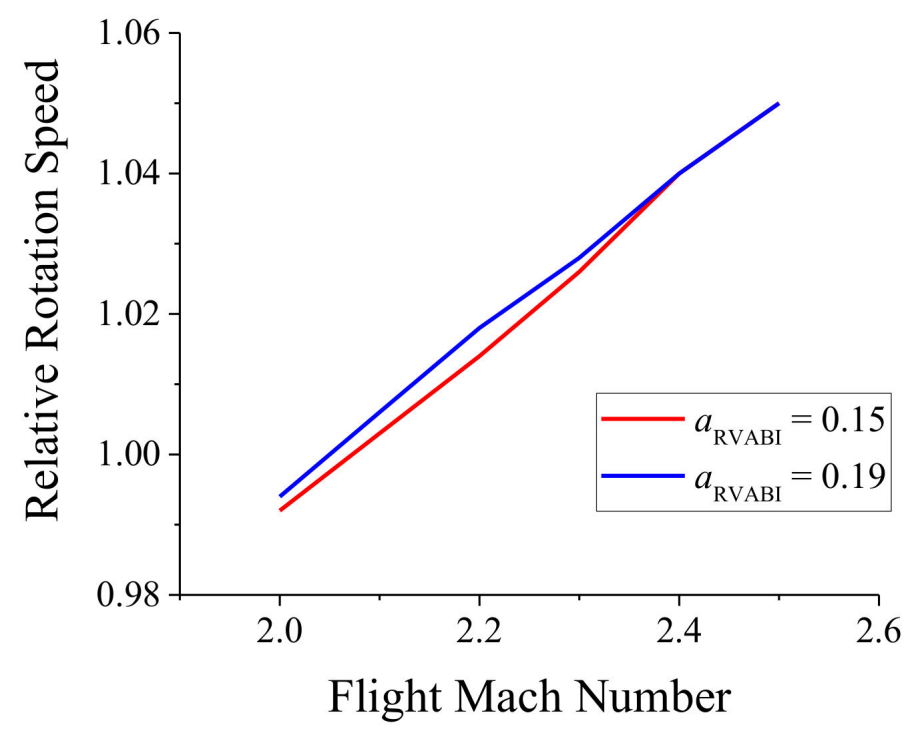

Figure 29. The Variations of Relative Rotation Speed of High-Pressure Shaft at the conditions of Different Area Coefficients of RVABI $\left(\alpha_{\text {RVABI }}\right)$. 


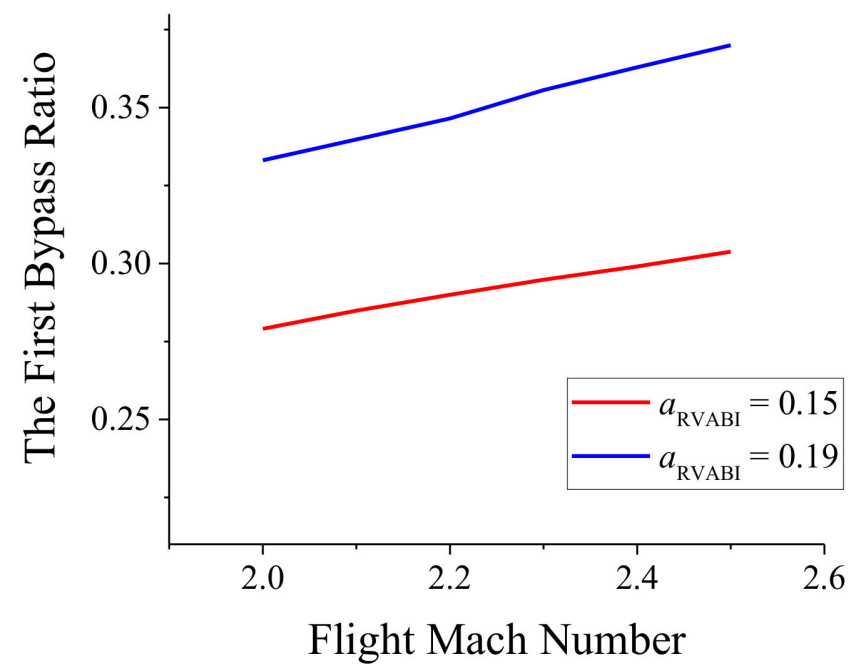

Figure 30. The Variations of The First Bypass Ratio at the conditions of Different Area Coefficients of $\operatorname{RVABI}\left(\alpha_{\text {RVABI }}\right)$.

The decrease of back pressure at the outlet of AFS will enhance the flow capacity of both the front fan and AFS. Therefore, the pressure ratio of the front fan decreases, and its matching point moves to the blocking boundary of its characteristic diagram, and then its surge margin increases. According to the calculation results, the changing trends of pressure ratios and surge margins of both the front fan and AFS are consistent with those in the theoretical analysis above (shown in Figures 31-33). This shows that the influence of RVABI adjustment on the co-operation of the front fan is mainly realized by the matching point change of AFS. This indirect influence way will reduce the influence degree of adjustment and make the changing range of front fan co-operating is relatively small.

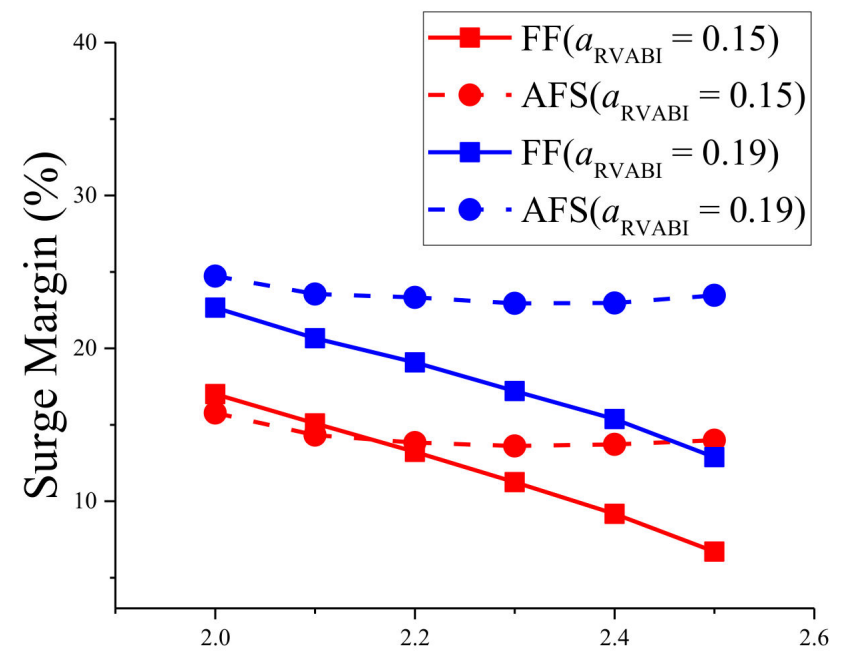

Flight Mach Number

Figure 31. The Variations of Surge Margins of Front Fan and AFS at the conditions of Different Area Coefficients of RVABI ( $\left.\alpha_{\text {RVABI }}\right)$. 


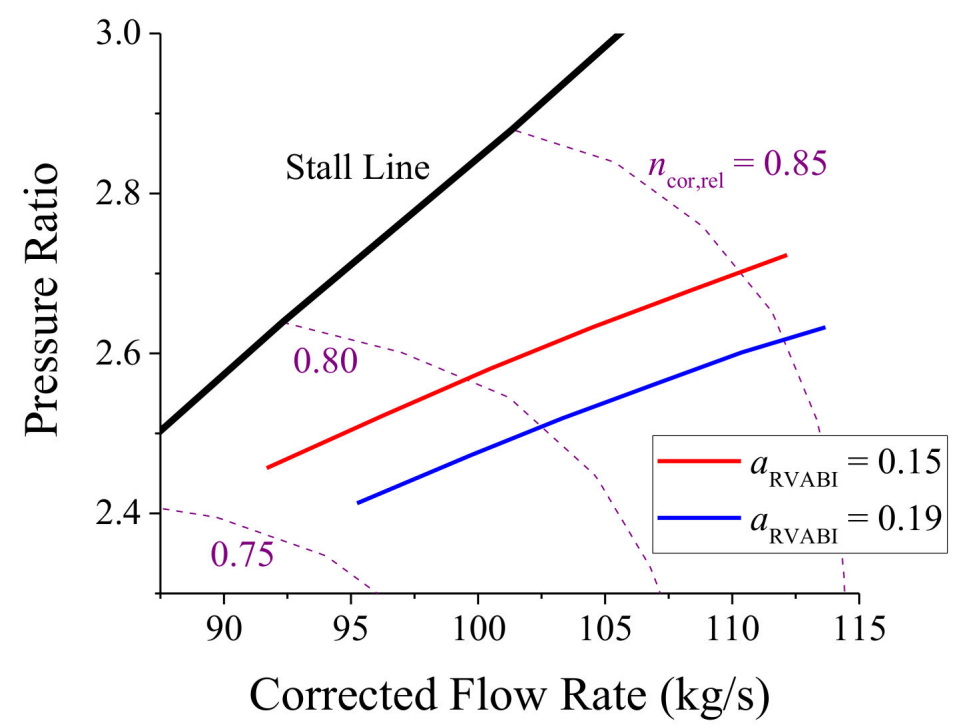

Figure 32. The Variations of the Matched Operating Lines of Front Fan at the conditions of Different Area Coefficients of RVABI $\left(\alpha_{\text {RVABI }}\right)$.

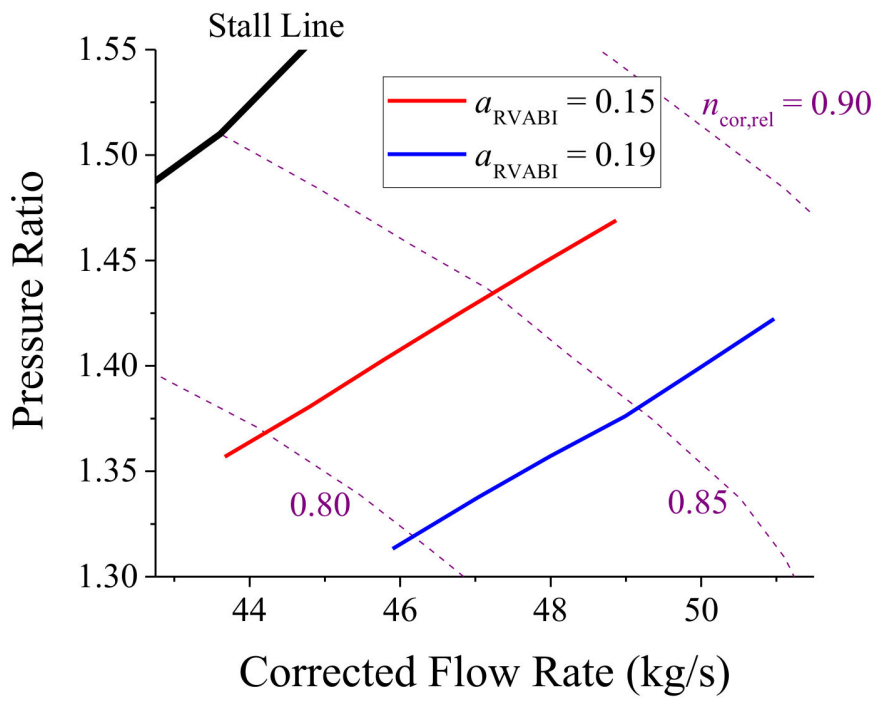

Figure 33. The Variations of the Matched Operating Lines of AFS at the conditions of Different Area Coefficients of RVABI $\left(\alpha_{\text {RVABI }}\right)$.

Based on the previous analysis, adjusting RVABI can ameliorate the FSRB matching problem, and appropriately increasing the area coefficient of RVABI can increase the surge margins of both front fan and AFS.

\subsection{High-Pressure Turbine}

The adjustment of inlet guide vane of high-pressure turbine mainly changes its pressure ratio and flow capacity by changing the throat area of guide vane, and then affects the co-operation of high-pressure compressor. Those compressing components upstream highpressure compressor, are also affected indirectly by temperature, pressure and flow rate.

When control schedule is maintaining the rotation speed of the low-pressure shaft, although the adjustment of the inlet guide vane throat of high-pressure turbine can change the pressure ratio of high-pressure turbine, turbine entry temperature will not significantly change because this adjustment has little effect on the pressure ratio of the low-pressure turbine (shown in Figure 34). When the throat area of the high-pressure turbine inlet guide vane increases, the pressure ratio of high-pressure turbine decreases, and the output power 
of high pressure turbine also decreases. Therefore, the rotation speed of high-pressure shaft decreases slightly, and then the pumping capacity of high-pressure compressor weakens. As a result, the AFS is blocked to a certain extent, and its surge margin is slightly reduced. More air flow has to flow into the first bypass and the first bypass ratio slightly increases. At a higher flight Mach number, which makes turbine entry temperature reach the limitation, the rotation speed of low-pressure shaft has to decrease, and FSRB matching phenomenon will also deteriorate.

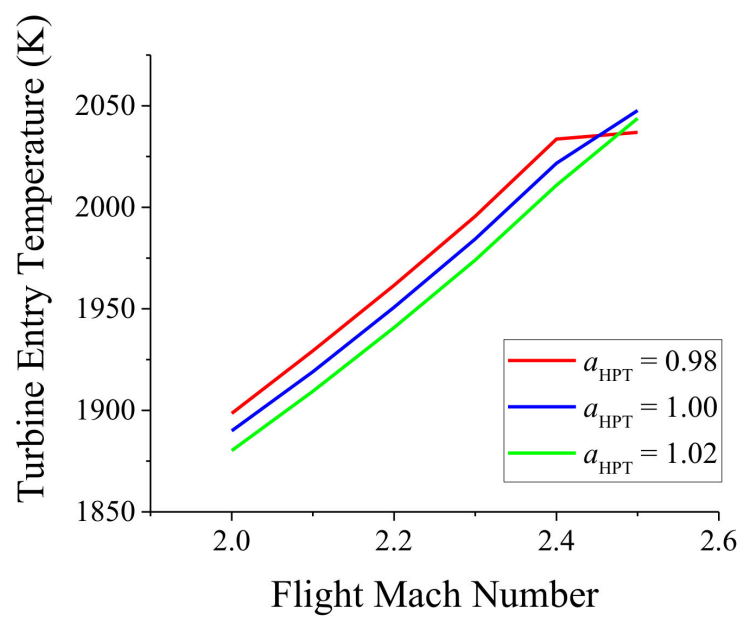

Figure 34. The Variations of Turbine Entry Temperature at the conditions of Different Throat Area Coefficients of High-Pressure Turbine Inlet Guide Vane $\left(\alpha_{\mathrm{HPT}}\right)$.

According to those calculation results, the adjustment of high-pressure turbine inlet guide vane only has sight influences on component co-operation, and the matching points of both the front fan and AFS do not change significantly (shown in Figure 35). Therefore, it can be considered that adjusting the high-pressure turbine inlet guide vane is not conducive to ameliorating the FSRB-matching phenomenon.

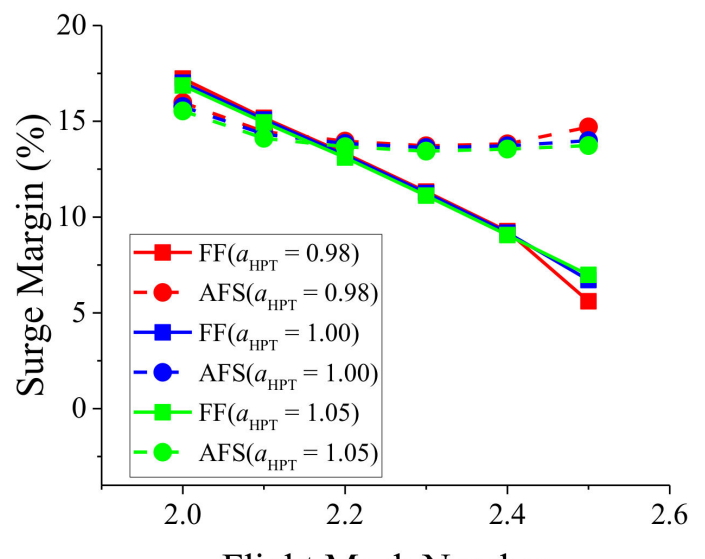

Flight Mach Number

Figure 35. The Variations of Surge Margins of Front Fan and AFS at the conditions of Different Throat Area Coefficients of High-Pressure Turbine Inlet Guide Vane $\left(\alpha_{\mathrm{HPT}}\right)$.

\subsection{Low-Pressure Turbine}

The adjustment of low-pressure turbine inlet guide vane also changes its throat area, thus mainly affecting the pressure ratio of both high-pressure turbine and low-pressure turbine and the flow capacity of low-pressure turbine. This kind of multi-factor change will have many complex influences on the component matching of ACE.

According to the calculation results, when the throat is of low-pressure turbine inlet guide vane increases, the turbine entry temperature decreases (shown in Figure 36), and the 
rotation speed of high-pressure shaft increases (shown in Figure 37), and the first bypass ratio decreases (shown in Figure 38). At the same time, surge margins of both the front fan and AFS slightly increase (shown in Figure 39).

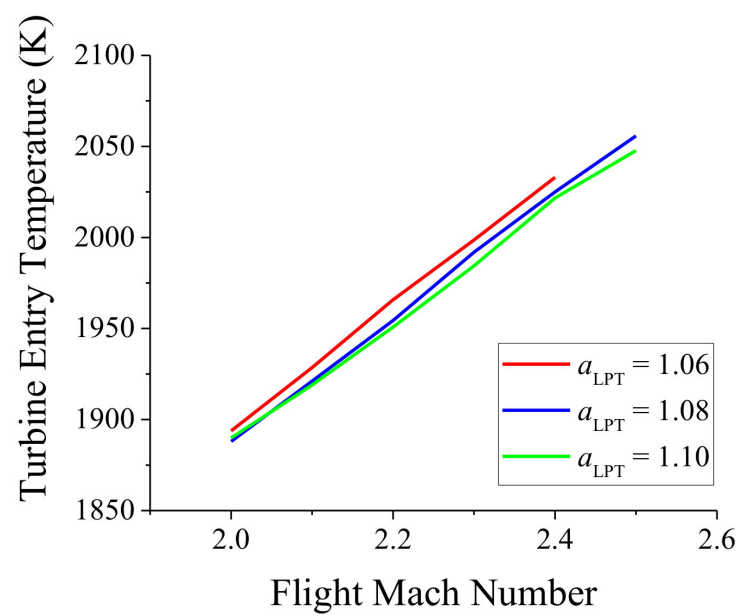

Figure 36. The Variations of Turbine Entry Temperature at the conditions of Different Throat Area Coefficients of Low-Pressure Turbine Inlet Guide Vane $\left(\alpha_{\mathrm{LPT}}\right)$.

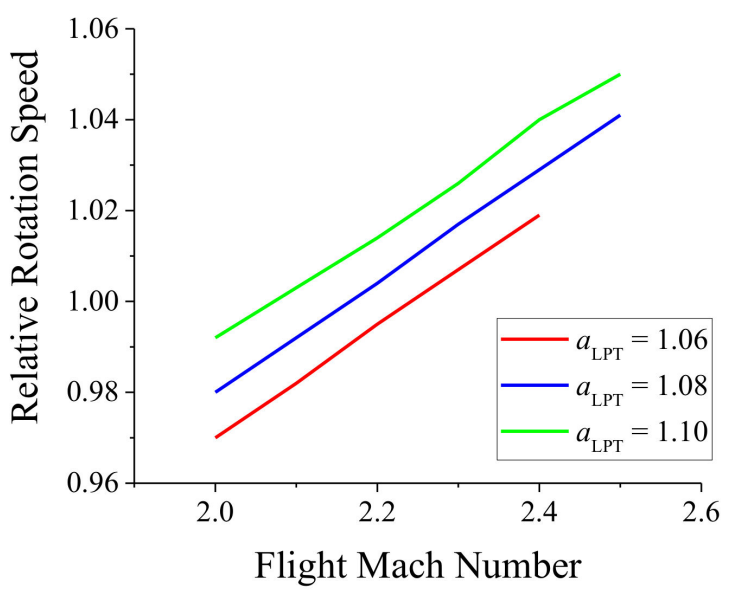

Figure 37. The Variations of Relative Rotation Speed of High-Pressure Shaft at the conditions of Different Throat Area Coefficients of Low-Pressure Turbine Inlet Guide Vane $\left(\alpha_{\mathrm{LPT}}\right)$.

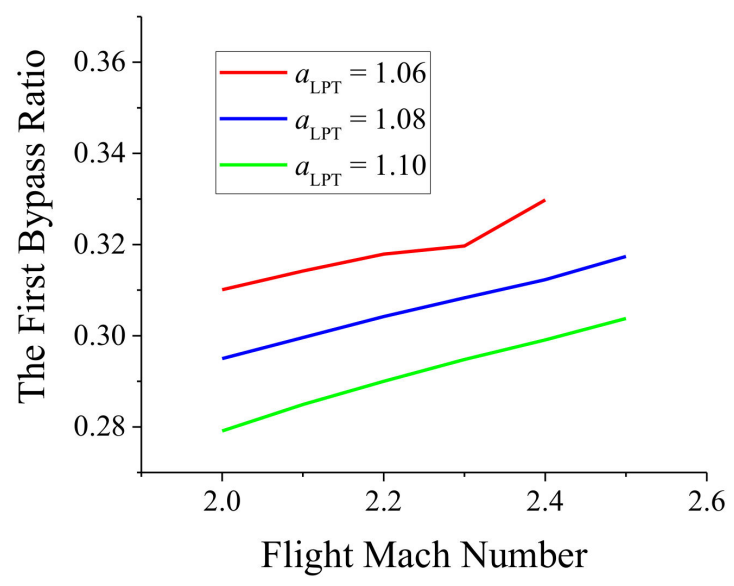

Figure 38. The Variations of The First Bypass Ratio at the conditions of Different Throat Area Coefficients of Low-Pressure Turbine Inlet Guide Vane $\left(\alpha_{\mathrm{LPT}}\right)$. 


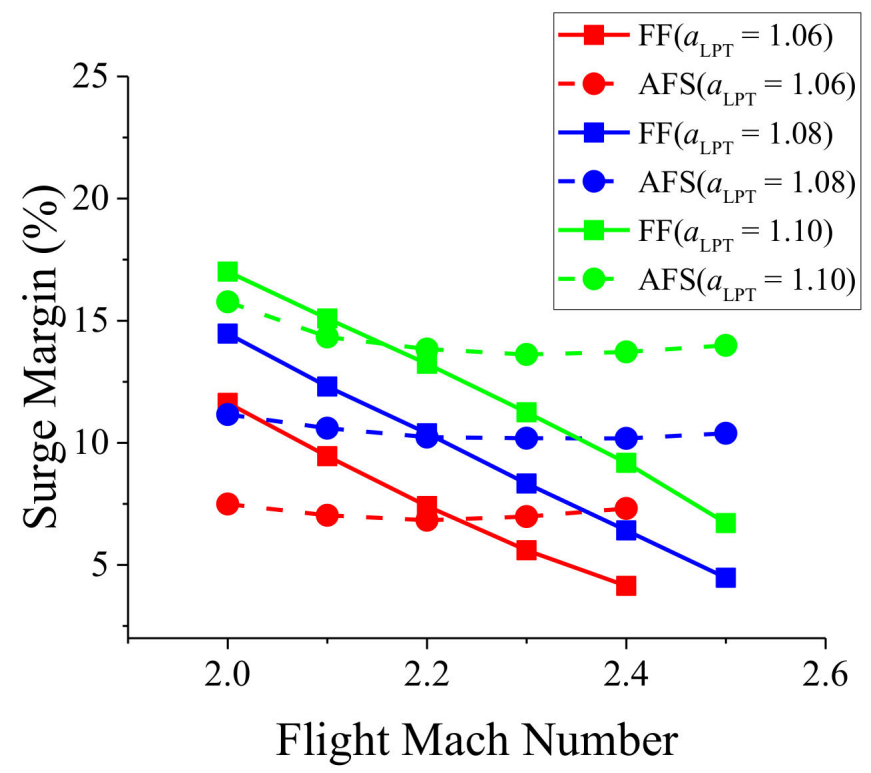

Figure 39. The Variations of Surge Margins of Front Fan and AFS at the conditions of Different Throat Area Coefficients of Low-Pressure Turbine Inlet Guide Vane $\left(\alpha_{\mathrm{LPT}}\right)$.

On the characteristic diagram of the front fan (shown in Figure 40), with the throat area increasing of low-pressure turbine inlet guide vane, the matched operating line is far away from the surge boundary, and pressure ratio decreases, as well as both the flow capacity and surge margin increase. On the characteristic diagram of AFS (shown in Figure 41), the matched operating line is also far away from the surge boundary. Its pressure ratio is reduced, and the flow capacity is slightly enhanced, as well as the surge margin increases.

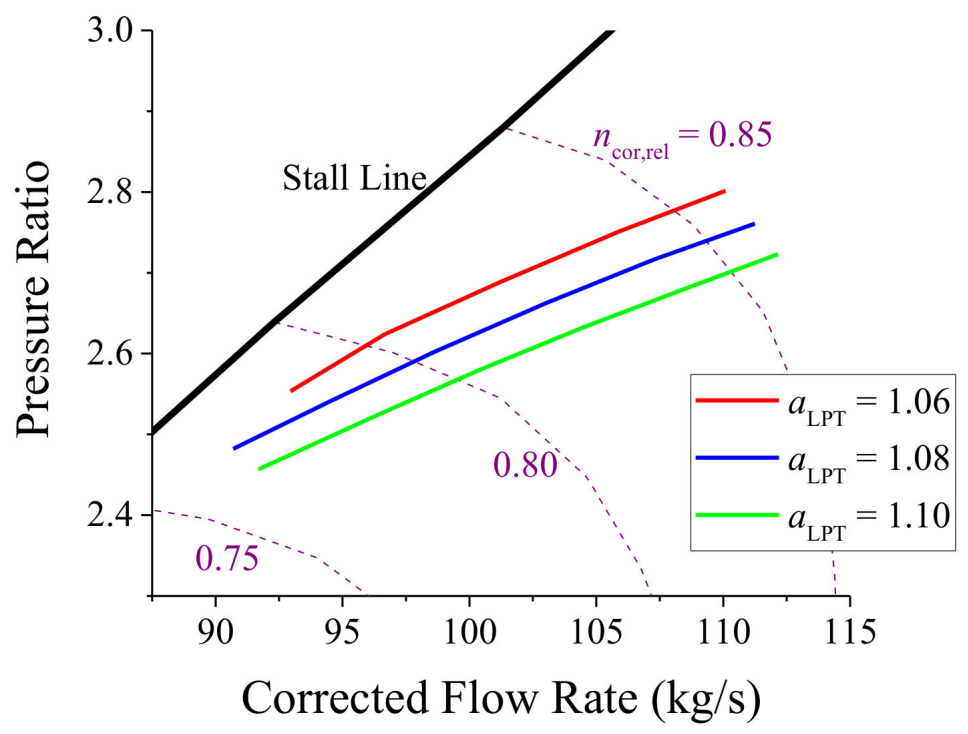

Figure 40. The Variations of the Matched Operating Lines of Front Fan at the conditions of Different Throat Area Coefficients of Low-Pressure Turbine Inlet Guide Vane $\left(\alpha_{\mathrm{LPT}}\right)$. 


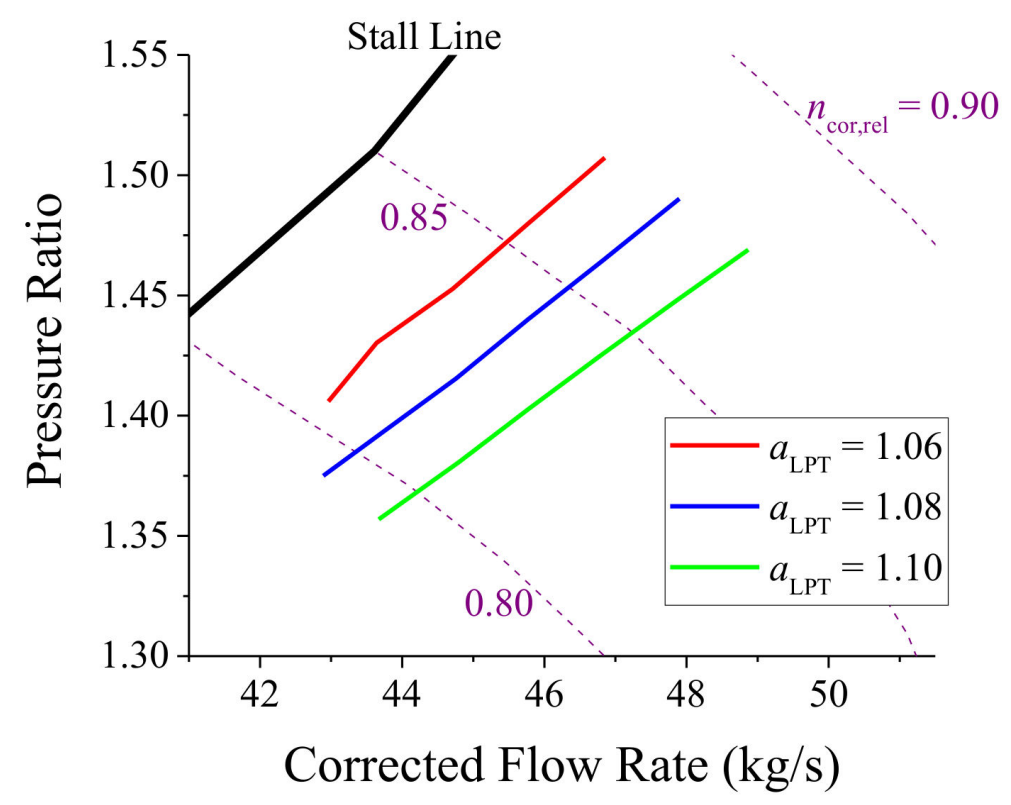

Figure 41. The Variations of the Matched Operating Lines of AFS at the conditions of Different Throat Area Coefficients of Low-Pressure Turbine Inlet Guide Vane $\left(\alpha_{\mathrm{LPT}}\right)$.

The change of turbine entry temperature is mainly analyzed through the work balance of low-pressure shaft. Because there are too many factors influencing on turbine entry temperature when the throat area of low-pressure turbine inlet guide vane and some of these influence trends are opposite to the other, it is difficult to make an accurate qualitative analysis of the overall trend. These factors can only be discussed qualitatively one by one, and the overall changing trend can finally be explained quantitatively with the calculation results. Under the condition of maintain the rotation speed of the low-pressure shaft, those factors influenced turbine entry temperature are listed as follow when the throat area of the low-pressure turbine inlet guide vane increases.

- The pressure ratio of low-pressure turbine decreases (shown in Figure 42), and then turbine entry temperature has increasing trend.

- The flow capacity of the front fan is enhanced (shown in Figure 40). The flow rates of both the front fan and AFS increase, and the compressing power of low-pressure compressing components has increasing trend at the same time. So, turbine entry temperature has increasing trend.

- The first bypass ratio decreases (shown in Figure 38), and then the flow rates of both air flow into core engine and gas flow into low pressure turbine are increased. So, turbine entry temperature has decreasing trend.

- The pressure ratios of both the front fan and AFS decrease (shown in Figures 40 and 41), and the compressing power of low-pressure compressing components has decreasing trend at the same time. So, turbine entry temperature has decreasing trend.

- The efficiencies of both the front fan and AFS increase (shown in Figure 43), and the compressing power of low-pressure compressing components has decreasing trend at the same time. So, turbine entry temperature has decreasing trend.

With the combined action of these factors mention above, when the throat area of lowpressure turbine inlet guide vane increases, turbine entry temperature decreases according to the calculation results.

The change of rotation speed of high-pressure shaft is also affected by several factors. When the throat area of the low-pressure turbine inlet guide vane increase, the increasing trend of high-pressure shaft comes from the increasing trend of high-pressure turbine work caused by the decreased pressure ratio of high-pressure turbine (shown in Figure 42), and the decreasing trend of high-pressure shaft comes from the decreasing trend of high-pressure 
turbine work caused by the decreased turbine entry temperature. According to the calculation results, the rotation speed of high-pressure shaft finally increases under the combined action.

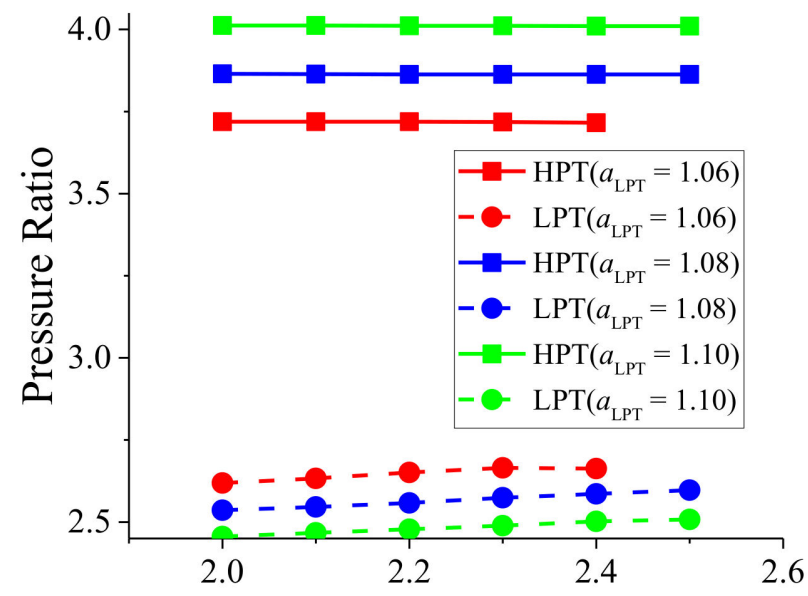

Flight Mach Number

Figure 42. The Variations of Turbine Pressure Ratios at the conditions of Different Throat Area Coefficients of Low-Pressure Turbine Inlet Guide Vane $\left(\alpha_{\mathrm{LPT}}\right)$.

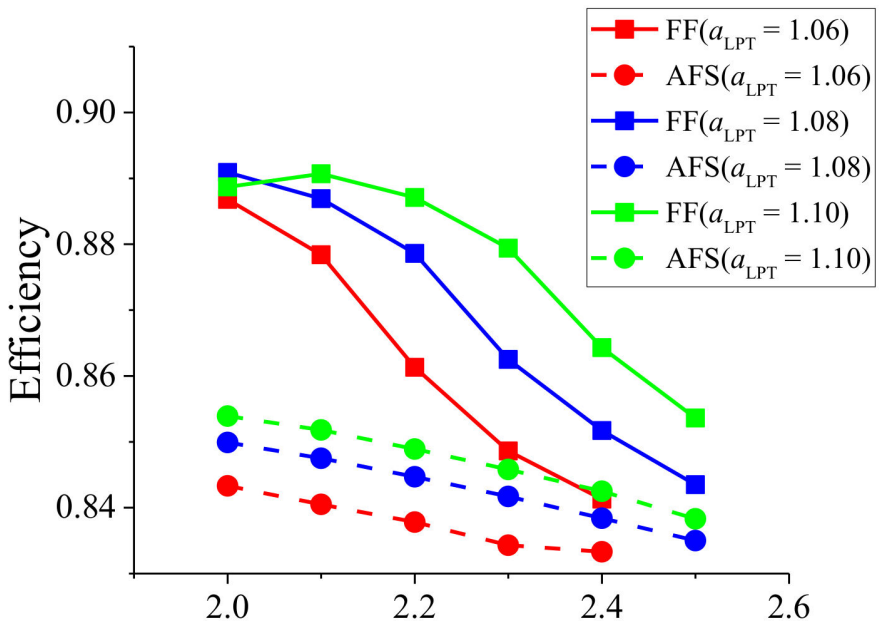

Flight Mach Number

Figure 43. The Variations of Efficiencies of Front Fan and AFS at the conditions of Different Throat Area Coefficients of Low-Pressure Turbine Inlet Guide Vane $\left(\alpha_{\mathrm{LPT}}\right)$.

According to those above calculation results, although the surge margin of the front fan is still reduced to a small value to cause FSRB phenomenon at higher engine inlet total temperature, the adjustment of low-pressure turbine inlet guide vane is considered to ameliorate FSRB problem in some extent due to the surge margin improvement of both the front fan and AFS.

After the analysis of those four variable geometry mechanisms, it could be concluded that the adjustment of either main nozzle or high-pressure turbine inlet guide vane has little influence on FSRB problem, and the adjustment of either RVABI or low-pressure turbine inlet guide vane could ameliorate FSRB problem in some extent without changing the variation trends of matched operating lines on component characteristic diagrams. Moreover, there are some other limitations in these adjustments. One of main limitations is that, the excessive throat area increases of low-pressure turbine inlet guide vane will further increase turbine entry temperature, which will reach its limitation at a relatively lower 
Mach number and cause the decrease the rotation speed of low-pressure shaft prematurely, thus aggravating FSRB problem. Another is that, when MSV is closed, the increasing range of RVABI area coefficient is also limited in order to match those components upstream afterburner. As a conclusion, even if the second bypass ratio is designed appropriately, the variable geometry adjustment is still difficult to completely solve FSRB problem.

\section{Conclusions}

This paper mainly discusses a ("front stall \& rear blockage" (FSRB) matching problem founded in the steady-state performance research of ACE with CFS. After analyzing the causes of FSRB problem, the feasibility of solving this problem is discussed from three aspects: the influence of component characteristics, the chosen of design cycle parameters and the adjustment of variable geometry mechanism. The specific conclusions can be summarized as follows:

(i) The cause of FSRB problem is that, when MSV is closed, both the flow capacities and flow rate adjustment capacities of Front Fan and AFS are not matched. Because Front Fan and AFS are both connected to the low-pressure shaft and the matching problem cannot be ameliorated by slip adjustment, the FSRB problem will inevitably occur.

(ii) The change ranges of both flow capacity between different inlet guide vane angles and the flow capacity at a certain corrected rotation speed of AFS Characteristic mainly affect the intensity of FSRB problem.

(iii) The design second bypass ratio is the most important design cycle parameter affecting FSRB problem. Without replacing the component characteristics used in this paper, a smaller design of the second bypass ratio can ameliorate FSRB problem in some extent, and expand the upper limit of available flight Mach number for Mode 1 with or without afterburning.

(iv) By adjusting either RVABI or low-pressure turbine inlet guide vane, the intensity of FSRB problem of an ACE designed with a low second bypass ratio can only be alleviated in some extent, but it is still impossible to completely solve this matching problem.

Author Contributions: Conceptualization, Z.Z. and M.C.; methodology, X.M. and Z.Z.; software, X.M. and Z.Z.; validation, X.M. and Y.X.; formal analysis, X.M.; investigation, X.M.; resources, Z.Z.; data curation, X.M. and Y.X.; writing-original draft preparation, X.M.; writing-review and editing, X.M., Y.X. and M.C.; visualization, X.M. and Y.X.; supervision, Z.Z.; project administration, M.C.; funding acquisition, M.C. All authors have read and agreed to the published version of the manuscript.

Funding: This research was funded by the National Natural Science Foundation of China (NSFC), grant number 51776010 and 91860205.

Institutional Review Board Statement: Not applicable.

Informed Consent Statement: Not applicable.

Data Availability Statement: The data presented in this study are available on request from the corresponding author. The data are not publicly available due to intellectual property rights of numeric simulation code and confidentiality of some data.

Acknowledgments: Meng thanks H. Tang, J. Zhangand X. Jia at Beihang University for providing much help and advice. The authors are also thankful for the support from Collaborative Innovation Center of Advanced Aero-Engine.

Conflicts of Interest: The authors declare no conflict of interest. 


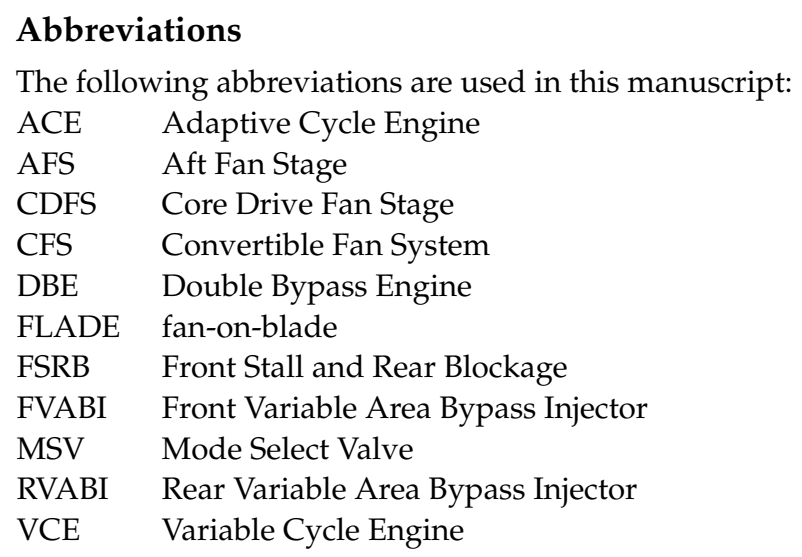

\section{References}

1. Tripak, J.A. The Sixth Generation Fighter. Air Force Mag. 2009, 92, 38-42.

2. Berton, J.J.; Haller, W.J.; Senick, P.F.; Jones, S.M.; Seidel, J.A. A Comparative Propulsion System Analysis for the High-Speed Civil Transport. NASA/TM 2005, 213414, 2005.

3. Brazier, M.E.; Paulson, R.E. Variable Cycle Engine Concept. In Presented at the International Society for Air Breathing Engines (ISABE); American Institute of Aeronautics and Astronautics: Tokyo, Japan, 1993.

4. Johnson, J. Variable cycle engines-The next step in propulsion evolution. In Proceedings of the 12th Propulsion Conference: American Institute of Aeronautics and Astronautics (AIAA), Palo Alto, CA, USA, 26-29 July 1976; Volume 28, pp. 1-38.

5. Murthy, S.N.B.; Curran, E.T. Variable cycle engine developments at general electric- 1955-1995. Developments in high-speed vehicle propulsion systems. Prog. Astronaut. Aeronaut. 1996, 165, 105-158.

6. Allan, R. General Electric Company variable cycle engine technology demonstrator programs. In Proceedings of the 15th Joint Propulsion Conference; American Institute of Aeronautics and Astronautics (AIAA), Las Vegas, NV, USA, 18-20 June 1979; pp. 18-20.

7. Ballal, D.R.; Zelina, J. Progress in Aeroengine Technology (1939-2003). J. Aircr. 2004, 41, 43-50. [CrossRef]

8. Nascimento, M.A.R.; Pilidis, P. An optimisation-matching procedure for variable cycle jet engines. In ASME 1992 International Gas Turbine and Aeroengine Congress and Exposition; International Gas Turbine Institute: Cologne, Germany, 1991; Volume 2, p. V002T02A029.

9. Tagashira, T.; Sugiyama, N. A performance optimization control of variable cycle engines. In Proceedings of the 39th AIAA/ASME/SAE/ASEE Joint Propulsion Conference and Exhibit, Huntsville, AL, USA, 20-23 July 2003.

10. Denney, R.K.; Tai, J.C.; Kestner, B.K.; Mavris, D.N. Mavris, Variable cycle optimization for supersonic commercial applications. In Proceedings of the Aerotech Congress \& Exhibition, Grapevine, TX, USA, 3-6 October 2005.

11. Ge Aviation. GE Adaptive Cycle Engine. 2018. Available online: https://www.geaviation.com/military/engines/ge-adaptivecycle-engine (accessed on 4 February 2021).

12. Bin, L.; Min, C.; Zhu, Z.L.; Kun, Z. Steady performance investigationon various modes of an adaptive cycle aero-engine. J. Propuls. Technol. 2013, 34, 1009-1015.

13. Simmons, R.J. Design and Control of a Variable Geometry Turbofan with an Independently Modulated Third Stream. Ph.D. Thesis, Aerospace Engineering, Ohio State University, Columbus, OH, USA, 2009.

14. Lyu, Y.; Tang, H.; Chen, M. A Study on Combined Variable Geometries Regulation of Adaptive Cycle Engine during Throttling. Appl. Sci. 2016, 6, 374. [CrossRef]

15. Meng, X.; Zhu, Z.-L.; Chen, M. Steady-State Performance Comparison of Two Different Adaptive Cycle Engine Configurations In Proceedings of the 53rd AIAA/SAE/ASEE Joint Propulsion Conference; American Institute of Aeronautics and Astronautics (AIAA), Atlanta, GA, USA, 10-12 July 2017.

16. Zheng, J.; Chen, M.; Tang, H. Matching mechanism analysis on an adaptive cycle engine. Chin. J. Aeronaut. 2017, 30, 706-718. [CrossRef]

17. Zheng, J.; Tang, H.; Chen, M.; Yin, F.-J. Equilibrium running principle analysis on an adaptive cycle engine. Appl. Therm. Eng. 2018, 132, 393-409. [CrossRef]

18. Patel, H.R. Parametric Cycle Analysis of Adaptive Cycle Engine. Master's Thesis, Aerospace Engineering, The University of Texas at Arlington, Arlington, TX, USA, 2016.

19. Chen, M.; Zhang, J.; Tang, H. Performance Analysis of a Three-Stream Adaptive Cycle Engine during Throttling. Int. J. Aerosp. Eng. 2018, 2018, 1-16. [CrossRef]

20. Chen, M.; Zhang, J.; Tang, H. Interval analysis of the standard of adaptive cycle engine component performance deviation. Aerosp. Sci. Technol. 2018, 81, 179-191. [CrossRef]

21. Zhang, J.; Tang, H.; Chen, M. Robust design methodologies to the adaptive cycle engine system performance: Preliminary analysis. Energy Procedia 2019, 158, 1521-1529. [CrossRef] 
22. Xu, Y.; Chen, M.; Tang, H. Preliminary Design Analysis of Core Driven Fan Stage in Adaptive Cycle Engine. In Proceedings of the 53rd AIAA/SAE/ASEE Joint Propulsion Conference; American Institute of Aeronautics and Astronautics (AIAA), Atlanta, GA, USA, 10-12 July 2017.

23. Mattingly, J.D.; Heiser, W.H.; Pratt, D.T. Aircraft Engine Design, 2nd ed.; AIAA Education Series; American Institute of Aeronautics and Astronautics: Reston, VA, USA, 2003.

24. Walsh, P.P.; Fletcher, P. Design Point Performance and Engine Concept Design. In Gas Turbine Performance, 2nd ed.; Blackwell Science Ltd.: Oxford, UK, 2004.

25. Walsh, P.P.; Fletcher, P. Off Design Performance. In Gas Turbine Performance, 1st ed.; Blackwell Science Ltd.: Oxford, UK, 2004.

26. Kurzke, J.; Halliwell, I. Propulsion and Power: An Exploration of Gas Turbine Performance Modeling; Springer: Berlin, Germany, 2018.

27. Kurzke, J. The Mission Defines the Cycle: Turbojet, Turbofan and Variable Cycle Engines for High Speed Propulsion. Presented at the NATO-OTAN, Dachau, Germany, September 2010. Available online: https:/ / www.semanticscholar.org/paper/The-Mission-Definesthe-Cycle\%3A-Turbojet\%2C-Turbofan-Kurzke/f723b25bc6ba854a3b8bfa13e5705a55e0f450fc (accessed on 4 February 2021).

28. Kim, S.; Kim, K.; Son, C. Three-dimensional unsteady simulation of a multistage axial compressor with labyrinth seals and its effects on overall performance and flow characteristics. Aerosp. Sci. Technol. 2019, 86, 683-693. [CrossRef]

29. Righi, M.; Pachidis, V.; Könözsy, L.; Pawsey, L. Three-dimensional through-flow modelling of axial flow compressor rotating stall and surge. Aerosp. Sci. Technol. 2018, 78, 271-279. [CrossRef]

30. Fuller, E.; Smith, C. Integrated CFD modeling of gas turbine combustors. In Proceedings of the 29th Joint Propulsion Conference and Exhibit; American Institute of Aeronautics and Astronautics (AIAA), Monterey, CA, USA, 28-30 June 1993.

31. Kurzke, J. Advanced user-friendly gas turbine performance calculations on a personal computer. In Proceedings of the ASME 1995 International Gas Turbine and Aeroengine Congress and Exposition, Houston, TX, USA, 5-8 June 1995; pp. 1-8.

32. Kurzke, J. How to get component maps for aircraft gas turbine. In Proceedings of the ASME 1996 International Gas Turbine and Aeroengine Congress and Exposition, Birmingham, UK, 10-13 June 1996; pp. 1-7.

33. Merz, R.; Krückels, J.; Mayer, J.F.; Stetter, H. Computation of Three-Dimensional Viscous Transonic Turbine Stage Flow Including Tip Clearance Effects; Gas Turbine and Aeroengine Congress and Exposition; ASME International: Houston, TX, USA, 1995.

34. Shi, J.; Wang, Z.; Zhang, X.; Zhou, L.; Sun, X. Performance estimation for fluidic thrust vectoring nozzle coupled with aero-engine. In Proceedings of the 50th AIAA/ASME/SAE/ASEE Joint Propulsion Conference, Cleveland, OH, USA, $28-30$ July 2014.

35. Turner, M.G.; Reed, J.A.; Ryder, R.; Veres, J.P. Multi-fidelity simulation of a turbofan engine with results zoomed in to mini-maps for a zero-D cycle simulation. In Turbo Expo: Power for Land, Sea, and Air; NTRS: Vienna, Austria, 2004.

36. Liu, B.; Wang, R.; Yu, X. On the mode transition of a double bypass variable cycle compression system. Aerosp. Sci. Technol. 2020 98, 105743. [CrossRef]

37. Klein, C.; Reitenbach, S.; Schoenweitz, D.; Wolters, F. A Fully Coupled Approach for the Integration of 3D-CFD Component Simulation in Overall Engine Performance Analysis. In Proceedings of the ASME Turbo Expo 2017: Turbomachinery Technical Conference and Exposition, Charlotte, NC, USA, 26-30 June 2017.

38. Sullivan, T.J.; Parker, D.E. Design Study and Performance Analysis of a High-Speed Multistage Variable-Geometry Fan for a Variable Cycle Engine; General Electric Company Aircraft Engine Group: Cincinnati, OH, USA, 1979.

39. Tang, H.L.; Zhang, J. A study of object-oriented approach for aeroengine performance simulation. J. Aerosp. Power 1999, 14, 421-424.

40. Chen, M.; Tang, H.; Zhang, K.; Hui, O.; Wang, Y. Turbine-based combined cycle propulsion system integration concept design. Proc. Inst. Mech. Eng. Part G 2012, 227, 1068-1089. [CrossRef]

41. Chen, M.; Zhu, Z.L.; Zhu, D.M.; Zhang, J.; Tang, H.L. Performance analysis tool for turbine based combined cycle engine concept. J. Astronaut. 2006, 27, 854-859.

42. Dong, P.; Tang, H.; Chen, M. Study on multi-cycle coupling mechanism of hypersonic precooled combined cycle engine. Appl. Therm. Eng. 2018, 131, 497-506. [CrossRef]

43. Dong, P.C.; Tang, H.L.; Chen, M. Overall performance design of paralleled heat release and compression system for hypersonic aero-engine. Appl. Energy 2018, 220, 36-46. [CrossRef]

44. Polichuk, D.; Teoh, K.H.; Zhang, Y.; Ellens, K.W.; Reed, D.W.; Covello, P.S. Nucleotide Sequence Encoding an Alcohol Dehydrogenase from Artemisia Annua and Uses Thereof. U.S. Patent 20110162097, 26 December 2010.

45. Bartsch, T.M.; Posson, C.W. Developing a Fighter Engine Derivative of the B-1/F101 Engine. In SAE Technical Paper Series; SAE International: Warrendale, PA, USA, 1980.

46. Inozemtsev, A.A.; Sulimov, D.D.; Khairullin, M.F. The Ps-90a Aircraft Engine and Its Industrial Derivatives; International Society for Air Breathing Engines (ISABE): Busan, Korea, 2013.

47. Taylor, R.; Byrd, F.; Young, E. Using Derivative engine technology to achieve maturity goals. In Proceedings of the 22nd Joint Propulsion Conference; American Institute of Aeronautics and Astronautics (AIAA), Huntsville, AL, USA, 16-18 June 1986.

48. Chenoweth, M.; Boito, M.; McKay, S.; Laureijs, R. Applying Best Practices to Military Commercial-Derivative Aircraft Engine Sustainment: Assessment of Using Parts Manufacturer Approval (PMA) Parts and Designated Engineering Representative (DER) Repairs; RAND Corporation: Santa Monica, CA, USA, 2016. 